\title{
Paths to Successful Translation of New Therapies for Severe Traumatic Brain Injury in the Golden Age of Traumatic Brain Injury Research: A Pittsburgh Vision
}

\author{
Patrick M. Kochanek, ${ }^{1,2}$ Travis C. Jackson, ${ }^{1,2}$ Ruchira M. Jha, ${ }^{1,2}$ Robert S.B. Clark, ${ }^{1,2}$ David O. Okonkwo, ${ }^{3}$ \\ Hülya Bayır, ${ }^{1,2,4}$ Samuel M. Poloyac, ${ }^{1,5}$ Amy K. Wagner, ${ }^{1,6}$ Philip E. Empey,,7 Yvette P. Conley, ${ }^{8}$ \\ Michael J. Bell, ${ }^{9}$ Anthony E. Kline, ${ }^{1,6}$ Corina O. Bondi, ${ }^{1,6}$ Dennis W. Simon, ${ }^{1,2}$ Shaun W. Carlson, ${ }^{1,10}$ \\ Ava M. Puccio, ${ }^{3}$ Christopher M. Horvat, ${ }^{1,2}$ Alicia K. Au, ${ }^{1,2}$ Jonathan Elmer, ${ }^{11}$ Amery Treble-Barna, ${ }^{1,6}$ \\ Milos D. Ikonomovic, ${ }^{12,18}$ Lori A. Shutter, ${ }^{2}$ D. Lansing Taylor, ${ }^{13}$ Andrew M. Stern, ${ }^{14}$ Steven H. Graham, ${ }^{15,18}$ \\ Valerian E. Kagan, ${ }^{4}$ Edwin K. Jackson, ${ }^{16}$ Stephen R. Wisniewski, ${ }^{17}$ and C. Edward Dixon ${ }^{10,15}$
}

\begin{abstract}
New neuroprotective therapies for severe traumatic brain injury (TBI) have not translated from pre-clinical to clinical success. Numerous explanations have been suggested in both the pre-clinical and clinical arenas. Coverage of TBI in the lay press has reinvigorated interest, creating a golden age of TBI research with innovative strategies to circumvent roadblocks. We discuss the need for more robust therapies. We present concepts for traditional and novel approaches to defining therapeutic targets. We review lessons learned from the ongoing work of the pre-clinical drug and biomarker screening consortium Operation Brain Trauma Therapy and suggest ways to further enhance pre-clinical consortia. Biomarkers have emerged that empower choice and assessment of target engagement by candidate therapies. Drug combinations may be needed, and it may require moving beyond conventional drug therapies. Precision medicine may also link the right therapy to the right patient, including new approaches to TBI classification beyond the Glasgow Coma Scale or anatomical phenotyping-incorporating new genetic and physiologic approaches. Therapeutic breakthroughs may also come from alternative approaches in clinical investigation (comparative effectiveness, adaptive trial design, use of the electronic medical record, and big data). The full continuum of care must also be represented in translational studies, given the important clinical role of pre-hospital events, extracerebral insults in the intensive care unit, and rehabilitation. TBI research from concussion to coma can cross-pollinate and further advancement of new therapies. Misconceptions can stifle/misdirect TBI research and deserve special attention. Finally, we synthesize an approach to deliver therapeutic breakthroughs in this golden age of TBI research.
\end{abstract}

\footnotetext{
${ }^{1}$ Safar Center for Resuscitation Research, UPMC Children's Hospital of Pittsburgh, Pittsburgh, Pennsylvania, USA.

${ }^{2}$ Department of Critical Care Medicine, University of Pittsburgh School of Medicine, Pittsburgh, Pennsylvania, USA.

${ }^{3}$ Department of Neurological Surgery, UPMC Presbyterian Hospital, Pittsburgh, Pennsylvania, USA.

${ }_{5}^{4}$ Department of Environmental and Occupational Health, University of Pittsburgh School of Medicine, Pittsburgh, Pennsylvania, USA.

${ }^{5}$ University of Pittsburgh School of Pharmacy, Pittsburgh, Pennsylvania, USA.

${ }^{6}$ Department of Physical Medicine and Rehabilitation, University of Pittsburgh School of Medicine, Pittsburgh, Pennsylvania, USA.

${ }^{7}$ Pharmacy and Therapeutics, University of Pittsburgh School of Pharmacy, Pittsburgh, Pennsylvania, USA.

${ }^{8}$ Health Promotion and Development, University of Pittsburgh School of Nursing, Pittsburgh, Pennsylvania, USA.

${ }^{9}$ Department of Critical Care Medicine, Children's National Medical Center, Washington, DC, USA.

${ }^{10}$ Department of Neurological Surgery, University of Pittsburgh School of Medicine, Pittsburgh, Pennsylvania, USA.

${ }^{11}$ Departments of Emergency Medicine and Critical Care Medicine, University of Pittsburgh School of Medicine, UPMC Presbyterian Hospital, Pittsburgh, Pennsylvania, USA.

${ }^{12}$ Department of Psychiatry, University of Pittsburgh School of Medicine, Pittsburgh, Pennsylvania, USA.

${ }^{13}$ University of Pittsburgh Drug Discovery Institute, University of Pittsburgh, Pittsburgh, Pennsylvania, USA.

${ }^{14}$ Drug Discovery Institute, Department of Computational and Systems Biology, University of Pittsburgh, Pittsburgh, Pennsylvania, USA.

${ }^{15}$ Geriatric Research Education and Clinical Center, VA Pittsburgh Healthcare System, Pittsburgh, Pennsylvania, USA.

${ }^{16}$ Department of Pharmacology and Chemical Biology, University of Pittsburgh, Pittsburgh, Pennsylvania, USA.

${ }^{17}$ University of Pittsburgh Graduate School of Public Health, Pittsburgh, Pennsylvania, USA.

${ }^{18}$ Department of Neurology, University of Pittsburgh School of Medicine, Pittsburgh, Pennsylvania, USA.
} 
Keywords: clinical trial design; combination therapy; consortium; traumatic brain injury (TBI); neuroprotection; pharmacodynamics/response biomarker; phenotyping; quantitative systems pharmacology; rehabilitation; target engagement

\section{Introduction}

$\mathbf{T}$ RAUMATIC BRAIN INJURY (TBI) is a critical public health problem. As outlined by the Centers for Disease Control and Prevention, ${ }^{1}$ in the United States each year an estimated 2.8 million Americans present to an emergency room with a TBI. As a consequence of these injuries, $\sim 282,000$ people are hospitalized, 56,000 people die, and $\sim 80,000-90,000$ experience long-term disability. To date, across the spectrum of TBI severity, from mild to severe, new neuroprotective therapies have not translated from pre-clinical to clinical success. Increased public awareness of the scope of the problem over the past decade has precipitated a surge in TBI research funding, notably from the U.S. Department of Defense and a number of foundations. Searching the Web of Science database comparing the terms TBI and stroke, the number of manuscripts published on TBI have tripled, whereas those on stroke have doubled in the last decade. ${ }^{2}$ Similarly, the number of manuscripts identified by a search of PubMed now number $>12,000$, with a robust increase seen after 2012 (Fig. 1). This surge in investigation has created a golden age of TBI research, during which many exciting new initiatives have been launched.

At the Safar Center for Resuscitation Research in the University of Pittsburgh School of Medicine, scientists are studying TBI in collaboration with investigators locally, across various departments and schools in the University, and through national and international collaborations. We have straddled bench and bedside in an attempt to facilitate new therapy development in TBI, along with linking the latest pre-clinical science to studies in patients, including the use of novel pre-clinical approaches, development of novel therapies and new clinical diagnostics, and use of advanced clinical trial design. Recent examples of that work encompass the full age spectrum from TBI in infants to elderly adults. ${ }^{3-7}$ Much of that work has been focused on severe TBI, given the fact that a substantial component of our investigative group is studying neurocritical care aspects of TBI along with research efforts in rehabilitation to maximize recovery from functionally devastating neurological injuries.

In this review, we discuss a number of state-of-the-art and futuristic investigative concepts and strategies that we and others have been exploring in an attempt to circumvent the roadblocks to therapy translation for TBI (Fig. 2). We consider the need for "better" and more robust therapies, along with identifying a number of therapeutic targets across the injury spectrum. The ongoing work of the pre-clinical drug and biomarker screening consortium Operation Brain Trauma Therapy (OBTT) has generated success and produced lessons for designing and enhancing preclinical consortia. We also propose that it is critical to assess both brain pharmacokinetics of therapies and monitor successful target engagement by candidate therapies-in both the pre-clinical and clinical arenas, using monitoring biomarkers and/or pharmacodynamics/response biomarkers, as outlined by the U.S. Food and Drug Administration (FDA). ${ }^{8}$

Drug combinations may be needed, and it may also be necessary to move beyond conventional drug therapies. Precision medicine approaches may help link the right therapy to the right patient at the right time and for the optimal duration (throughout the continuum of care, from acute care through rehabilitation), and we present novel precision medicine approaches that we are currently

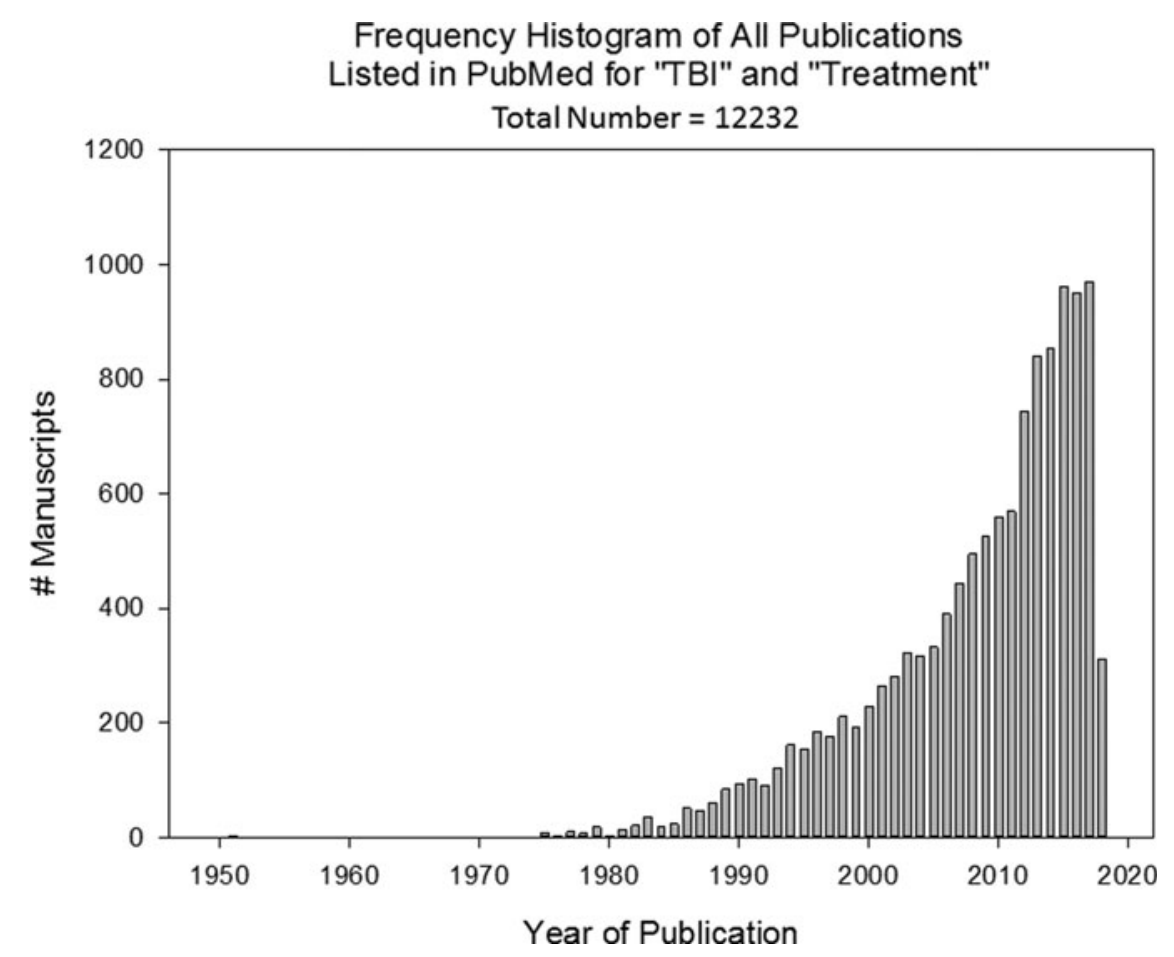

FIG. 1. Frequency histogram of the number of publications listed in PubMed for the search terms TBI and treatment. A marked uptick is seen after 2011. Note that the value for 2018 is based on the accessing of PubMed on September 3, 2018. TBI, traumatic brain injury. 


\section{Strategies to facilitate therapy development and translation in TBI}

\begin{tabular}{|c|c|}
\hline Pre-clinical & Clinical \\
\hline Identify more robust therapies & Neurotection vs \\
\hline symptom based therapy
\end{tabular}

FIG. 2. Strategies in both the pre-clinical and clinical arenas that will be presented and discussed in this review to facilitate therapy development and successful clinical translation in the setting of severe traumatic brain injury. Please see text for details. PD, pharmacodynamics; PK, pharmacokinetics.

exploring. We also discuss exciting new developments in clinical investigation, including comparative effectiveness trials, adaptive trial design, use of continuous data acquisition, electronic medical record, and big data, to generate large sample sizes with a wealth of phenotypic data and biological characterization from which to assess treatment effects. This also includes studies to delineate the heterogeneity inherent to clinical populations, along with efforts to use reverse translational approaches involving in vivo, in vitro, and in silico models to study how this heterogeneity impacts injury, recovery, and treatment response. There is also value in studying the full continuum of care in translational designs, given the powerful clinical role of events in the pre-hospital arena, extracerebral insults in the intensive care unit (ICU), and the impact of rehabilitation on outcome. We also touch upon the interface between TBI research across the spectrum of severity and how severe and mild TBI investigations can inform each other to synergize the advancement of new therapies. Finally, we address important issues that may be producing misconceptions with regard to therapy development that, if not carefully and objectively discussed, could stifle or misdirect TBI research. Together, this collective body of work suggests that therapeutic breakthroughs are on the horizon in the golden age of TBI research.

\section{Better Drugs or Therapies}

The failure of translation of therapies to clinical success in TBI is often blamed on a laundry list of limitations in the current design of clinical trials. Most clinical trials of new therapies have focused on severe TBI, so much of the criticism has been about studies in that arena. Limitations include issues such as marked heterogeneity of TBI pathology (contusion, diffuse axonal injury, subdural hematoma, etc.), heterogeneity in patient characteristics (age, sex, secondary insults, etc.) and personal biology, regional differences in the emergency and critical care that is provided (lack of level 1 evidence for standard therapy), variability in surgical approaches that may be taken, great heterogeneity of rehabilitation provided both in hospital and after discharge, and lack of assessment of pharmacokinetics and pharmacodynamics for the novel therapies being tested in patients. Also, genetic differences in response to both TBI and therapy are not being considered in pre-randomization screening or in post-hoc assessment of treatment efficacy. Further criticisms include insufficiently sensitive outcome assessment tools (Glasgow Outcome Scale; GOS), inadequately powered trials, particularly for one-size-fits-all trials-and many other concerns. Although these concerns are important, recent studies in the field of stroke have suggested that an alternative or additional limitation may underlie the failure of treatment trials-namely, that the drugs or other therapies being tested are simply not sufficiently robust to produce a meaningful improvement in outcome.

Similar to TBI, many randomized clinical trials (RCTs) of pharmacological approaches have failed to improve outcome in stroke. However, recent groundbreaking studies in stroke have demonstrated highly significant beneficial effects on outcome in several RCTs of clot retrieval. These trials have reported large effects, $>30 \%$ differences between groups. $^{9-11}$ Several of these trials have met stopping criteria for efficacy with fewer than the projected number of patients (as few as 70 patients) as a result of these large effects. Similarly, benefit of therapeutic hypothermia in 
term newborn infants with hypoxic-ischemic encephalopathy has been demonstrated in multiple trials on mortality, short- and longterm neurological outcome, and structural preservation on imaging. ${ }^{12}$ Differences between treated and control groups in the range of $20-25 \%$ or more are generally observed.

These studies suggest the need to rethink the singular focus on clinical trial design as the key culprit in the failures of clinical trials in TBI, and suggest that we also need to develop more robust therapies. They also suggest that the heterogeniety and myriad confounders of TBI may be overcome with a sufficiently potent therapy, though it is unclear whether or not any pharmacological approach in TBI can produce a benefit of the magnitude that matches the impact of rapid reperfusion (resulting from clot retrieval) in patients with stroke or of hypothermia in the newborn brain. Indeed, the effects observed in RCTs of various pharmacological therapies in severe TBI have been small, generally $<10 \%$ difference between groups. ${ }^{13-15}$ Taken together, these findings strongly suggest the need to improve therapy selection (i.e., more robust therapies) and/or therapy development/optimization for clinical trials in TBI. How might we approach the development of "better" therapies?

\section{Therapeutic Targets for Traumatic Brain Injury}

Better therapies mandate the need to identify key therapeutic targets. The golden age of TBI research has been fostered, to a considerable degree, by the recognition of the importance of repetitive concussions or mild TBI. Given the failure of therapy translation in studies focused largely on severe or moderate-tosevere TBI, novel thoughts on therapy development have emerged, outlining two general approaches. The traditional neuroprotectionbased approach is to identify and target key mechanisms involved in the evolution of secondary injury-whether in severe or mild TBI. In this traditional approach, treatment is generally initiated as early as possible after injury, given that it is believed that delaying neuroprotective therapies reduces their efficacy. Those therapies often target key initiators of the secondary injury cascade. An alternative approach, being studied in clinical trials of patients with mild TBI, is one of symptomatic (rather than mechanism-based) treatment—-targeting symptoms such as headache, sleep disorders, vestibular/oculomotor disturbances, post-traumatic stress disorder, cognitive dysfunction, or other secondary sequelae. This approach is the centerpiece of the recent work by the Targeted Evaluation, Action, and Monitoring of TBI (TEAM TBI) investigative group at the University of Pittsburgh Brain Trauma Research Center. ${ }^{16}$ TEAM TBI, in essence, uses symptomatic phenotyping to characterize patients, craft a targeted treatment regimen, and then monitor therapeutic progress. Such an approach is logical for mild TBI given the fact that, in many cases, patients with mild TBI do not present until well after their initial insult because of persistent symptoms. In addition, testing therapies in the acute phase in mild TBI, outside of the laboratory, is challenging given that most patients fully recover and predicting those who do not can be difficult. ${ }^{17}$ Nevertheless, many factors only partially linked to the TBI can contribute to persistent symptoms after mild TBI, including stress, psychological conditions, fatigue, and other factors. A symptombased approach has been standard in another facet of TBI care, namely rehabilitation, where patients are categorized based on symptom profiles rather than on Glasgow Coma Scale (GCS). ${ }^{18}$

Some acute treatments of severe TBI are based on "symptoms" or, more accurately, clinical or physiological findings, such as the use of therapies (hyperosmolar agents, barbiturates, hypothermia, and craniectomy) to mitigate intracranial hypertension, ${ }^{19-21}$ and certainly additional progress, including optimization of these treatments and development of new therapies targeting these physiological findings, are needed. Nevertheless, most of the focus in severe TBI has been on new neuroprotective agents. ${ }^{22-24}$ Purported key therapeutic targets in the evolution of secondary injury are well known, have been described in a number of cases by investigators in our center, and include mechanisms such as excitotoxicity, neuronal death, axonal injury, neuroinflammation, cerebral edema, synaptic damage, oxidative stress, mitochondrial failure/dysfunction, and ischemia, among others. Interestingly, although these categories of the secondary injury mechanisms are generally accepted, details of the targets are often less clearly defined.

We and others have taken the traditional approach to development of new neuroprotective therapies to address these questions in a classic mechanism-based approach in individual laboratories, generally using a single model or possibly two models. However, we have also overseen the development and investigations of a novel approach, namely, OBTT, a multi-center pre-clinical therapy and biomarker screening consortium. ${ }^{23,25-34}$ OBTT has provided considerable insight into the field of therapy development for neuroprotection in TBI.

\section{Pre-Clinical Consortia: Operation Brain Trauma Therapy}

Consortia-based approaches have great potential to address issues such as phenotypic heterogeneity, using multiple models, along with the ability to maximize rigor, using highly protocolized manual of operations-based blinding, randomization, execution, and rigorous data analysis. They also have the potential to identify therapies with the greatest possible effect size either across one or more TBI phenotypes (models). To this end, OBTT has brought together expert investigators in multiple centers to test therapies in three TBI models in rats. It uses conventional pre-clinical outcomes, advances promising therapies to testing in a gyrencephalic animal (micro pig), and incorporates the use of serum biomarkers of brain injury to develop them for theranostic applications. Details of OBTT and its findings have been published ${ }^{23,25-32,34}$ and recently reviewed. ${ }^{33}$ Briefly, in OBTT, we targeted two specific hypotheses, namely that 1 ) a robust therapy showing benefit across multiple pre-clinical models would have the best chance of demonstrating benefit when tested in a conventional RCT in severe TBI (which includes a broad range of anatomic phenotypes) and 2) each TBI model (and thus each clinical phenotype) needs a different precision therapy.

To address these hypotheses, we used three TBI models, namely parasagittal fluid percussion injury (FPI), controlled cortical impact (CCI), and penetrating ballistic-like brain injury. These models map to a range of clinical phenotypes such as contusion, diffuse injury, and penetrating injury, respectively. These were the principal rat models already established and heavily used in each of the three rodent screening centers. Central FPI in the micro pig was selected as the large animal model to test therapies, because it represented both a gyrencephalic TBI animal model executed by a highly experienced team and produced a more mild diffuse injury, not captured in the rat models.

OBTT represents only one approach to develop a TBI therapy screening consortium, albeit a logical first approach. It uses a scoring matrix that includes 22 points per rat model, assessed on multiple dimensions, including motor, cognitive, histological, and serum biomarker outcomes. ${ }^{23}$ A total of 12 therapies have been tested by OBTT, namely, nicotinamide, erythropoietin, cyclosporin 
A, simvastatin, levetiracetam, glibenclamide, kollidon VA64, amantadine, minocycline, E64d, and P7C3-A20. Two of the therapies, levetiracetam and glibenclamide, have shown the most promise, namely levetiracetam improved multiple outcomes in two models (FPI and CCI) and glibenclamide demonstrated fairly robust benefit in CCI, but with benefit largely restricted to that model. ${ }^{29,32,33}$

Many lessons have been learned from the work of OBTT. Using our screening approach, therapies have produced less robust benefit than expected from the published literature upon which many of the therapies were chosen and treatment regimens designed. This may have resulted from many factors, including limitations such as the lack of demonstration that the drug or dose selected effected the mechanism or mechanisms being targeted in each model, our preference for drug administration by the intravenous route (given the fact that severe TBI was the target), the fact that treatment effects were not powered for all of the outcomes assessed, and the high level of blinding and rigor in the execution and analysis of the studies that may not have been applied in previous studies, among other potential explanations. Nevertheless, because OBTT is a screening consortium, it seeks highly robust therapies that transcend subtle methodological differences between experimental protocols (such as differences in anesthesia, animal strain, vendor, age, diet, surgical approach, brain temperature, details of the injury, and others) that can greatly affect findings. ${ }^{35-37}$

Lithgow and colleagues ${ }^{38}$ in an article in Nature stated that it is a rare project that specifies methods with a high level of precision and that true standardization may be counterproductive-suggesting that it may be better to focus on robust results that persist across a wide range of conditions than to chase fragile findings that occur only within narrow parameters. That philosophy mirrors OBTT, given the reality of multi-center clinical research and general medical care. In OBTT, where rather than attempting to reproduce various modeling details at each site, highly robust therapeutic efficacy across multiple established models is sought. Given that both anatomical TBI phenotypes and injury severity vary greatly in clinical trials, such an approach is justified for in vivo therapy screening.

The two therapies identified as promising by OBTT (levetiracetam and glibenclamide) merit additional pre-clinical and clinical evaluation. Both are FDA-approved drugs for other uses (seizures and diabetes, respectively) and thus are candidates to advance to clinical investigation in TBI. Both also merit additional pre-clinical studies. For example, levetiracetam showed its greatest benefit in OBTT in the mildest model, parasagittal FPI in rats, and thus requires additional evaluation in mild TBI models. However, beyond these two agents, OBTT and other therapy screening consortia can be further enhanced by two additional strategies: 1) higher-throughput screening strategies to help select therapies that may generate a more robust effect in conventional in vivo approaches and 2) confirmation of target engagement at the doses and treatment regimens evaluated to maximize the chance to demonstrate efficacy in one or more models in vivo.

\section{Novel Approaches to Therapy Selection: Development of Clinically Relevant Phenotypic Screens and the Application of Quantitative Systems Pharmacology}

As discussed in a recent review about OBTT, ${ }^{33}$ a literature-based approach was used for therapy selection in OBTT. After additional recommendations from multiple sources, a table of potential therapies with a description of the key aspects and findings (species, dose, model, and behavioral, histological, and mechanistic outcomes) of all of the published studies in pre-clinical models of TBI was provided to the OBTT site principal investigators and a secret ballot vote was taken to rank the therapies. This was followed by a final ranking annually at a face-to-face OBTT investigators meeting. This process allowed us to leverage the literature; however, this approach is not systematic and is challenged by the many differences between published studies in dosing and treatment protocols, species, outcomes, and other parameters-making it difficult to rank therapies objectively. An alternative strategy is to screen therapies first in an in vitro TBI model, such as stretch injury in neuron or neuron/glial cultures. ${ }^{39-43}$

In addition to standard approaches targeting neuronal death, our group at the Safar Center has identified a novel in vitro approach, to mimic the in vivo environment in neuron/glial stretch models to highlight axonal injury without appreciable neuronal death. ${ }^{44}$ More sophisticated human systems biology models, such as three-dimensional organoids and microfluidic "organ-on-achip" approaches, have been developed and used in a variety of disease models, including the brain, ${ }^{45-48}$ although these types of systems remain exploratory for TBI. In vitro screening approaches are limited, at this point in time, in their ability to incorporate clinically relevant features of TBI such as alterations in perfusion, intracranial pressure (ICP), cerebral oxygenation, neuroinflammation, and other extracerebral factors, but organ-on-a-chip systems are evolving rapidly to include more pathophysiological functions. ${ }^{49}$

High throughput in vivo screening for leukemia has been carried out in zebrafish, as has TBI model development. ${ }^{50,51}$ Similarly, invertebrate TBI models, such as in drosophila, could be considered to screen therapies for TBI. ${ }^{52}$ Mathematical modeling — such as an approach targeting neuroinflammation-is also a consideration. ${ }^{53}$

Although technically feasible, the development and implementation of sophisticated models suitable for high-throughput drug screening that recapitulate clinical phenotypes of TBI and lead to translation of robust paradigms require new translational paradigms. Linear hierarchical paradigms involving standard, in vitro screening, in vivo testing, and traditional clinical trial designs may well be suited for cases where compelling evidence (i.e., genetic) exists supporting a one-gene, one-target, one-disease mechanism hypothesis. In contrast, for multi-factorial intrinsically heterogeneous disorders such as TBI, where the molecular basis for the set of discernable clinical phenotypes is not well understood, comprehensive and unbiased translational strategies, such as Quantitative Systems Pharmacology (QSP) ${ }^{54,55}$ as implemented in the Drug Discovery Institute, University of Pittsburgh ${ }^{54}$ that are network centric and can integrate, analyze, and validate large, complex data sets, may be needed.

QSP is a patient-focused iterative process of experimentation and computational modeling with each informing the other to converge on a comprehensive understanding of disease mechanism with increasing accuracy through each cycle. The iterative process identifies disease-specific emergent properties that lead to novel therapies and biomarkers mechanistically linked to disease progression. The pre-clinical in silico knowledge gained through the iterative steps guides clinical trial design, in which the trial itself now becomes an integral module of the iterative QSP cycle, generating additional patient data to further refine and cross-validate our pre-clinical models, deepen our understanding or the pathophysiology, and improve next-generation therapies. ${ }^{54}$ Thus, QSP as a translational platform complements and can be integrated with adaptive clinical trial designs (discussed below) that hold promise as a novel approach for TBI. 
As shown in Huntington's disease, ${ }^{56}$ QSP can be implemented in conjunction with a chemogenomics module where screening to identify drugs that modulate disease-relevant phenotypes can be conducted with genetic approaches and/or additional pharmacological agents. Computational and systems biology methods can then be implemented to extend the initial chemogenomic data set to include additional drugs and place individual targets into pathways. The identification through experimentation and computational modeling of individual drugs that act synergistically in combinations is an important next step to identify emergent disease-specific interactions between pathways implicated in the clinical phenotype. The use of known drugs as mechanistic probes of relevant phenotypes in TBI and the prospect of repurposing them alone or in combination could accelerate development of robust therapeutic strategies.

\section{Additional Approaches to Therapy Screening Consortium Design}

OBTT has focused on the development of acute therapies for severe TBI. However, there are many possibilities for multi-center pre-clinical therapy screening. A logical opportunity for preclinical consortium development is to study mild TBI and repetitive mild TBI. Given the importance of long-term outcomes, and the link and common mechanisms underlying TBI and neurodegenerative diseases, a consortium could also focus on long-term outcome testing therapies targeting neurodegeneration after severe or mild repetitive TBI in conventional animal models, as well as in transgenic animals modeling altered metabolic pathways known to contribute to abnormal protein aggregation (i.e., tau, amyloid- $\beta$, and $\alpha$-synuclein), relevant to an increased risk of chronic neurodegenerative disorders after TBI. ${ }^{57}$

Studies have been published, by our group and others, in the CCI and FPI models assessing 1-year chronic outcomes, which revealed dramatic targets, including progressive tissue loss and persistent cognitive deficits. ${ }^{58,59}$ Mild TBI models would also be important to include. The approach to therapy testing in a long-term outcome consortium could include 1) acute treatment, 2) delayed chronic treatment, and 3) acute plus chronic therapy. Some studies of TBI in individual centers have begun to take these types of approaches. ${ }^{60,61}$ These long-term studies would also represent perfect opportunities to incorporate environmental enrichment ${ }^{62}$ or experimental cognitive training strategies ${ }^{63}$ with and without drug therapy mimicking clinical care in TBI rehabilitation. Approaches to pre-clinical consortium composition targeting key TBI and treatment scenarios in rodent and/or gyrencephalic species were previously reviewed by OBTT. ${ }^{33}$ An additional approach to consortium design would be based on TBI phenotype. For example, one might envisage a consortium of investigators studying therapies targeting intracranial hypertension in models that produce focal contusion and diffuse swelling, which likely involve different mechanisms. Therapies designed to either prevent the development of cerebral edema, or reduce it once it has reached a critical level, could be evaluated. Many other phenotype-based modeling consortia merit consideration. Finally, recommendation on approach to consortium design for proclinical testing were also recently summarized by the Moody Project investigative group. ${ }^{64}$

\section{Target Engagement-Related Pre-Clinical Strategies to Enhance the Success of Clinical Translation}

Whether therapies are developed in individual laboratories or by consortia, it may be critically important for any therapy to clearly define the therapeutic target or targets and demonstrate, in both preclinical and ultimately in clinical investigations, that successful target engagement has been achieved. This is essential to defining an optimal dose and treatment regimen. Unfortunately, in TBI, it is unclear whether the simple strategy to confirm similar serum drug exposure across pre-clinical and human studies is sufficient. Studies defining optimal drug exposure across multiple TBI models for a given therapy have been lacking in pre-clinical investigations. Defining drug exposure in one or two models is unlikely to maximize the chance for successful translation given the marked anatomic, genetic, and physiological heterogeneity in human TBI. This concern is even greater for drugs with limited blood-brain barrier (BBB) permeability, given that the degree and location of $\mathrm{BBB}$ permeability varies across TBI phenotypes and injury severities (even within the same phenotype). This issue may have importantly contributed to failed clinical trials in the past, such as for polyethylene glycol-conjugated superoxide dismutase or Tirilazad. ${ }^{65,66}$

Two therapies have been the subject of extensive pre-clinical testing and large, multi-center RCTs, namely erythropoietin and progesterone. ${ }^{13-15,67}$ Clinical trials in $>3000$ patients for these two therapies in TBI failed to show benefit. As discussed above, many explanations for these failures have been suggested, often placing the lion's share of the blame on clinical trial design - given that pre-clinical studies in multiple laboratories and models have reported benefit. However, these drugs share the common properties that they are touted to target multiple mechanisms involved in the evolution of secondary injury in the brain after TBI while having low brain penetration. ${ }^{68,69}$ Although the concept that a pleiotropic drug targeting multiple mechanisms has often been suggested as being important to achieving therapeutic efficacy for TBI, pleiotropism creates a challenging scenario for successful clinical translation. If multiple mechanisms are targeted by a therapy, are they equally important across species, types of TBI, and/or in the face of myriad other confounders? Similarly, how does one scale and monitor dosing, therapeutic window, and other facets of drug development from pre-clinical to clinical investigations for these types of therapies? It is thus unclear as to exactly what specific mechanistic target or targets are essential to modulate to achieve efficacy. Such concerns arose for both erythropoietin and progesterone in pre-clinical or clinical TBI investigations. In addition, differences in endogenous sex hormone levels in both brain and serum, including progesterone and its estrogen-related metabolites, could further complicate the evaluation of progesterone's impact on neurological outcome. ${ }^{70,71}$

For both therapies, a marker of target engagement, in brain, was lacking to which therapeutic efficacy could be confirmed and/or titrated to effect. This limits the ability to optimize therapeutic efficacy, define whether or not therapies are robust, and ultimately may have contributed to the translation block that occurred. How might we address this deficiency in translational design? Looking back at OBTT, and to other disease processes, suggests opportunities to develop and use biomarkers to aid in defining the impact of new therapies on their targets, and link that information to the effects observed on various conventional outcomes.

In OBTT, the serum biomarker, glial fibrillary acidic protein (GFAP), was effective in ensuring model stability over the many studies and thus might serve to help stratify patients for a trial. GFAP also served as a useful pharmacodynamics/response biomarker (using the FDA categorization); a change in the biomarker shows that a biological response has occurred after a therapeutic intervention. ${ }^{8}$ For example, lower 24 -h serum levels of GFAP were associated with less hemispheric tissue loss (at 21 days after injury) 
for a therapy that was effective (i.e., levetiracetam). ${ }^{29}$ Serum biomarkers thus have the potential to serve as early post-injury indicators of ultimate therapeutic efficacy. This approach is being used by other researchers to evaluate pre-clinical and clinical drug efficacy. ${ }^{72,73}$ GFAP was also useful for identifying adverse effects. ${ }^{27,28}$ However, use of serum biomarkers like GFAP in this capacity, although of potential value for screening by individual laboratories or by a consortium, does not prove that target engagement with a specific receptor has occurred, rather that the biomarker serves as an early predictor of overall efficacy. Proving target engagement requires that the pharmacodynamics/response biomarker impacted its specific mechanistic target. Recent work by OBTT has shown that serum levels of phospho-neurofilament-H (pNF-H), a marker of axonal injury, can be used to identify therapeutic efficacy in the early or subacute period after injury. This suggests that pNF-H could potentially represent an example of a pharmacodynamics/response biomarker to rapidly assess therapies specifically targeting axonal injury and/or contributes to understanding of how therapies targeting other mechanisms impact axonal injury. A post-hoc assessment of samples from the OBTT biorepository also revealed that serum pNF-H levels at $48-72 \mathrm{~h}$ after TBI were also reduced by treatment with levetiracetam, suggesting either that this therapy has a specific effect on axonal injury or an overall benefit on neuronal death that mitigates secondary axonal loss. ${ }^{34}$ One could envision development of a variety of pharmacodynamics/response biomarkers to interrogate effects on specific secondary injury mechanisms for pre-clinical screening and clinical use. Such an approach could greatly enhance translation potential for therapies. Another example of this type of biomarker, also developed by our group in Pittsburgh, is the use of unique biomarkers in plasma originating from damaged organelles. Contemporary lipidomics analysis can reveal brain mitochondriaspecific molecular species of cardiolipins in plasma. ${ }^{74}$ These represent biomarkers of mitochondrial damage that could be used to monitor the effects of new therapies. Alternatively, tools such as magnetic resonance imaging (MRI), magnetic resonance spectroscopy, or microdialysis could serve to define target engagement $^{75-81}$ —indeed proof of target engagement for therapies in TBI is not limited to serum biomarkers.

Recently, our translational TBI research group in Pittsburgh used another type of pharmacodynamics/response biomarker, namely, cerebrospinal fluid (CSF) pharmacometabolomics to assess the impact of treatment with the combination of the antioxidant, $\mathrm{N}$-acetylcysteine (NAC), and the drug transport inhibitor, probenecid, on its key target, namely the glutathione pathway after severe TBI in children. ${ }^{5,82}$ Although NAC crosses the BBB, ${ }^{83}$ the CSF concentrations that are achieved are only a tiny fraction $(<0.1 \%)$ of those achieved in blood. ${ }^{5,83}$ This is partly because NAC is rapidly transported back into blood by the organic acid transporters 1 and 3. Probenecid inhibits those transporters and thus enhances brain exposure of NAC to levels measurable in human $\mathrm{CSF}^{83}$ NAC serves both as a direct antioxidant and a source for the synthesis of glutathione. Treatment with probenecid and NAC produced a significant alteration in the CSF metabolomic signature of TBI. Relative glutathione levels were increased $>600$-fold after treatment with NAC plus probenecid, and both pathway and network analyses showed that biochemical processes involving detoxification with glutathione and glutathione recycling were enriched by treatment verifying target engagement. ${ }^{5,83} \mathrm{CSF}$ metabolomics, in severe $\mathrm{TBI}$-where CSF is often available - thus has potential to serve as a pharmacodynamics/response monitor of target engagement by a given therapy in severe TBI. Not only can the primary target and its metabolites be assessed, but also other off-target and/or unanticipated effects can be interrogated. Similar metabolomics profiles could be envisaged for drugs targeting axonal injury, different facets of inflammation, excitotoxicity, mitochondrial injury, cerebral edema, or various neuronal death cascades.

Proteomic profiles may also be informative ${ }^{84}$ and serve as another type of pharmacodynamics/response biomarker. This includes studies of CSF. For example, data from human CSF in severe TBI revealed that there may be biomarker potential for sulfonylurea-receptor 1 (Sur1) to prognosticate secondary injury processes such as cerebral edema and/or intracranial hypertension. ${ }^{85}$ Sur1 combined with transient receptor cation channel 4 (Trpm4) creates an octameric cation channel that is only found in the central nervous system (CNS) after injury. This channel is inhibited by glibenclamide, one of the two drugs that showed benefit in OBTT (as previously discussed). Pathways such as this, with promising results in both pre-clinical and clinical studies, are logical to pursue. It is also noteworthy that NAC was recently shown to have beneficial effects in mild TBI resulting from blast injury in a clinical trial in 81 patients. $^{86}$

The aforementioned trial of NAC and probenecid ${ }^{5,82}$ also addressed the topic of combination therapy, which has been suggested to be difficult or impossible to bring to clinical trials, given the regulatory hurdles that are involved. Combination therapy could represent an important way to enhance the potency of various therapies-either joining to target a single mechanism (such as oxidative stress in this study) or targeting divergent mechanismswith additive or synergistic effects. A review of combination therapy in TBI is beyond the scope of this article, but the topic has been recently reviewed. ${ }^{87,88}$ The fact that this approach was able to be accomplished in children with severe TBI, given the many potential regulatory hurdles for combination therapy in clinical trials, suggests that it may be more feasible than previously thought and thus the potential of combination therapy may be able to be more fully explored.

\section{Novel Approaches to Precision Therapies in Traumatic Brain Injury: Anatomical, Genetic, and Physiological Phenotyping}

The need for phenotyping of TBI has been the subject of numerous reviews on the failures of therapy development and strategies for the future in TBI research. ${ }^{89-91}$ However, much of the focus on phenotyping in severe TBI has been on anatomical phenotyping - such as designating injury types like contusion, diffuse axonal injury, diffuse swelling, subarachnoid hemorrhage, subdural hematoma, and/or combinations of lesions. Other conventional approaches to phenotyping in severe TBI include assessing age, sex, injury mechanism, and injury severity (across the spectrum of severe TBI). Two other potential strategies for fully characterizing TBI heterogeniety merit discussion and have been the focus of a number of studies by our group and others.

A number of single-nucleotide polymorphisms (SNPs) have been identified in initial studies with small cohorts that may represent important tools for understanding heterogeneity in patients with severe TBI, with an advantage of SNPs being that they are stable biomarkers across tissues and time. Previous work includes assessing genetic variation in genes such as apolipoprotein E4, brain-derived neurotropic factor, dopamine transporter and D2 receptor, and catechol-O-methyltransferase, among others. ${ }^{92-96}$ These have most commonly been studied as they relate to short- or long-term outcome or TBI sequelae such as depression, behavioral 
dysfunction, and cognitive performance. Further innovations such as the concept of evaluating the effects of cumulative genetic load on cognitive performance have been reported. ${ }^{97}$

Germane to the concept of using SNPs to guide precision therapy development, several recent studies merit discussion. As previously discussed, OBTT identified glibenclamide as a therapy that merits additional exploration, specifically in the setting of contusion. However, it is well known that patients who present with contusions of similar size and location may have very divergent courses, ranging from relative stability to fulminant blossoming with malignant brain edema and the need for decompressive craniectomy. Recently, Jha and colleagues ${ }^{98,99}$ reported that four SNPs of the Sur1 gene (ABCC8) were strongly associated with markers of cerebral edema in a sample of $\sim 400$ adult patients with severe TBI. This included edema on head computed tomography scan, mean and peak ICP, and/or need for decompressive craniectomy. As mentioned above, Sur1 is the regulatory protein for opening of the Trpm4 non-selective cation channel, which has been shown to play a role in the development of brain edema and necrosis in preclinical models of TBI in the work of Simard and colleagues, ${ }^{100}$ Patel and colleagues, ${ }^{101}$ and others. ${ }^{102,103}$ Glibenclamide specifically blocks opening of the Sur1-Trpm 4 channel complex. Of note, the SNPs all map to the region of the Sur1 gene that codes for sites on the Sur1 protein that interact with Trpm4 within the channel region. ${ }^{99}$ The SNPs have minor allele frequencies of $20-40 \%$, and the minor alleles were associated with increased risk of cerebral edema whereas the major alleles were protective-suggesting an evolutionary advantage. It is thus tempting to speculate that based on the pre-clinical data from OBTT, a trial of glibenclamide in patients with contusion would have the best chance to show benefit, if it selected patients based on a rapid assay that identified genetically at-risk severe TBI patients likely to develop contusion expansion or malignant edema. Such a pre-randomization approach for Sur1 and other therapeutic targets is an exciting avenue for the future in TBI therapy development.

Poly-ADP ribose polymerase-1 (PARP-1) has been suggested in pre-clinical studies to represent another potential therapeutic target in TBI related to the energy depletion that is observed with PARP activation after brain injury. ${ }^{104}$ Similar to Sur-1, SNPs of the PARP-1 gene are associated with TBI outcomes, ${ }^{105}$ and it is possible that early pre-randomization patient selection for clinical trials of PARP1 inhibitors could aid in increasing the chance for trial success.

A similar approach also merits testing and could ultimately pay dividends with regard to therapy development for the treatment and/or prevention of post-traumatic seizures, given that SNPs of the adenosine $\mathrm{A} 1$ receptor, glutamate transporters, interleukin (IL)- $1 \beta$, and other genes have been associated with the development of either early or late post-traumatic seizures. ${ }^{106-108}$ Past pre-clinical work by our group demonstrated a bench to bedside translational link in these studies. We demonstrated that adenosine A1 receptor knockout mice develop lethal status epilepticus after $\mathrm{CCI}^{109}-\mathrm{a}$ finding that served as the basis for the human SNP studies. Similarly, our work showing neuronal glutamate transporter and IL-1 $\beta$ variation associations with accelerated epileptogenesis and increased post-traumatic epilepsy risk is complimented by recent preclinical data showing regionally reduced neuronal glutamate transporter expression and sustained increases in IL-1 $\beta$ levels that are reversible with daily Levetiracetam treatment. ${ }^{110}$ These studies support the potential for using genetic stratification to inform treatment response in the setting of post-traumatic epilepsy.

Beyond using genetic approaches for pre-randomization approaches, our TBI rehabilitation has been conducted in the context of a Rehabilomics framework wherein personal biology and other biomarkers are assessed in relation to the World Health Organization international classification of function, which consists of multi-dimensional assessment of function, including impairments, activities, and participation-based outcome metrics. ${ }^{111}$ This framework focuses on the complex interplay between personal, biological, psychosocial, and environmental factors to provide a foundation for evidence-based personalized rehabilitation care and management with the goal of extending our understanding and optimizing survivor based outcomes across the care continuum and their integration back into the community. ${ }^{112}$

It is well known that sample sizes of 200-500 patients that have been used for the SNP studies to date in TBI are at risk for false discovery. It is thus exciting that DNA repositories from the large, multi-center studies by TRACK TBI, CENTER TBI, and ADAPT are being generated to allow for replication, and point-of-care technologies for rapid genotyping are being developed to realize precision-based treatment of TBI patients in the acute setting. Additionally, with larger sample sizes, discovery-based genomewide approaches are possible for identifying both novel biomarkers and potential therapeutic targets.

Physiology-based phenotyping represents another potential approach to help enrich clinical trials with patients that have a greater chance to respond to novel therapy. Recently, we reported on the findings of trajectory analysis of ICP waveforms in $>400$ adult patients with severe TBI. ${ }^{7}$ Six ICP trajectory groups were identified, including groups characterized as low rising, persistently low, intermittent spikes, frequent spikes, almost persistent intracranial hypertension, and severe intracranial hypertension. As anticipated, the groups with almost persistent and severe intracranial hypertension had the highest rates of poor outcome, but surprisingly two of four groups with ICP levels $<20 \mathrm{~mm} \mathrm{Hg}$ (low rising, persistently low groups) also had relatively poor outcome versus the intermittent and frequent spike groups. The lack of ICP variability was also associated with unfavorable outcome. This study suggests the possibility that ICP trajectory or variability might be important tools to phenotype patients with severe TBI. This approach would be most relevant if a rapid assessment of ICP trajectory and/or waveform variability were able to be generated and be predictive. As one might imagine, this approach could also be of special importance to trials targeting the assessment of the value of ICP monitoring in severe TBI, given the recent controversy that has been raised over its value. ${ }^{113-116}$ Two other possible approaches to physiological phenotyping for testing of novel therapies in clinical trials of patients with severe TBI include the assessment of cerebral blood flow $(\mathrm{CBF})$ autoregulation and the assessment of brain tissue oxygen tension. Continuous monitoring of $\mathrm{CBF}$ autoregulation using pressure reactivity index (PRx) has been described since 2002, ${ }^{117}$ with levels $<0.25$ or 0.05 associated with survival or favorable outcome, respectively. ${ }^{118} \mathrm{PRx}$ could represent a logical way to dichotomize patients in clinical trials of therapies targeting CBF. It has already been used as a treatment target in a study on the use of hypertonic saline, and the calculated optimal cerebral perfusion pressure (CPP) based on PRx level has been shown to vary significantly between centers using different therapeutic regimens. ${ }^{119,120}$ Additional work by that same group has also revealed the potential utility of measures incorporating waveform analysis such as pulse amplitude index and correlation between ICP pulse amplitude and CPP. ${ }^{121,122}$

Similarly, the recent phase II study by Okonkwo and colleagues $^{123}$ of 119 adults with severe TBI using brain tissue oxygen monitoring (the BOOST-II trial), along with a number of other reports on the use of $\mathrm{PbtO}_{2}$ monitoring, support the potential utility 
of this monitoring modality to direct another approach to physiological phenotyping for patient selection in clinical trials of patients with severe TBI. Therapies targeting brain tissue hypoxia could be assessed in a targeted group with levels below a key threshold. This approach has been used for novel therapies in pre-clinical studies of TBI. ${ }^{124}$ Physiological phenotyping for therapy testing in clinical trials thus represents an underutilized approach with potential in the setting of severe TBI.

\section{Therapies Beyond Conventional Drugs}

A comprehensive review of therapy development in TBI is beyond the scope of this review. Nevertheless, it is important to mention the breadth of therapies that are currently in development for severe TBI. Beyond conventional drugs and combination therapy, approaches such as cell-based therapy, ${ }^{125-128}$ mitochondrialtargeting drugs, ${ }^{129-131}$ nanoparticle-based therapies, ${ }^{132}$ micro-RNAbased therapies, ${ }^{133}$ secretomes, ${ }^{134}$ approaches to enhance glymphatic flux ${ }^{135}$ novel therapies to block the production/accumulation of aggregation-prone proteins, such as the amyloid- $\beta$, tau, and $\alpha$ synuclein, ${ }^{57}$ nano-pulsed laser therapy, ${ }^{136}$ novel delivery systems such as the intranasal route or polymer implantation, ${ }^{137,138}$ and miniaturized implantable microbiosensors to monitor neurotransmitters, ${ }^{139}$ among other novel approaches, have shown potential in pre-clinical models of acute brain injury.

\section{Addressing the Full Continuum of Care: From Extracerebral Insults in the Field through to Rehabilitation}

Severe TBI often occurs in the setting of polytrauma and/or is complicated by additional insults such as hypotension, hypoxemia, hemorrhage, infection, fever, multiple organ failure, and other complications. Insults such as hypotension represent one of the most powerful determinants of outcome after severe TBI. ${ }^{140-142}$ Patients with secondary insults are almost always excluded from clinical trials of novel therapies. This is understandable given the fact that these second insults add further complexity to the aforementioned TBI phenotypes that already confound clinical trials. In addition, events that occur in the field immediately after injury may not be captured by medical personnel, thus resulting in unrecognized secondary injuries. What remains unclear is how the inclusion or study of these patients might impact therapeutic success. For example, it is unclear whether a patient with a severe primary injury who presents GCS 5 would be more or less likely to respond to a novel therapy than a patient who is also GCS 5, but with a less severe primary injury that was accompanied by a second insult, such as hypotension in the field. This could also be influenced by the choice of the therapy that is being tested. With only a few exceptions, such as the study of the use of fluids such as crystalloids or colloids in the field in TBI patients requiring resuscitation, patients with second insults represent an untapped opportunity for novel therapy development, particularly for treatments initiated in pre-hospital or emergency department care.

There are many integral facets of ICU management in the care of patients with severe TBI that could have a major impact on outcome. For example, across ICU care there is a move toward the use of early mobilization and early rehabilitation rather than prolonged sedation. ${ }^{143-146}$ The impact of this strategy on TBI outcomes merits investigation. Similarly, issues such as the optimal approach to nutrition-which is administered with marked heterogeneity across ICUs, and assessment and management of the microbiome, merit study both pre-clinically and in clinical trials, particularly given what appears to be a major impact of the microbiome on neuroinflammation and outcome in pre-clinical models of acute brain injury. ${ }^{147}$ This takes on greater importance given the links between TBI and the development of neurodegenerative diseases. ${ }^{57,148} \mathrm{Fi}$ nally, biomarkers that surveil for potential adverse effects in the ICU, including those reflecting the systemic response to injury or treatment, may also be needed.

Another important question with regard to the overall strategies that are most likely to succeed in TBI therapy development is whether the greatest emphasis should be placed on neuroprotection or rehabilitation. A commonly recognized concern is the fact that even if acute care of the severe TBI victim is tightly protocolized for the testing of a novel therapy in a multi-center trial, rehabilitation varies across centers-introducing considerable additional "silent" variability to the assessment of GOS at 6 months or 1 year after the injury. However, levels of analysis about rehabilitation treatments can be considered in the World Health Organization international classification. Treatments can be protocolized and potential mechanisms theoretically and empirically defined to better operationalize and understand their utility. ${ }^{149}$ Although there has been a growing literature developed with investigators at the Safar Center characterizing mechanisms underlying commonly used medications in rehabilitation care such as stimulants, anticonvulsants, and antipsychotics, ${ }^{109,150,151}$ the number of pre-clinical studies testing therapy development linking neuroprotection and rehabilitation are limited, such as the combination of a neuroprotective agent or cellular therapy with enriched environment (see previous works ${ }^{152-154}$; reviewed in another work ${ }^{155}$ ). These are important areas for future research to provide more insight as to how to optimize the injured brain in the acute setting to facilitate maximal efficacy of rehabilitation approaches.

\section{New Clinical Trial Design}

Four emerging advances in clinical trial design merit consideration to enhance therapy development for severe TBI: 1) comparative effectiveness studies; 2) adaptive trial design; 3) continuous data acquisition; and 4) big-data approaches. Several promising single-center studies of therapies in $\mathrm{TBI}^{15,156,157}$ have failed to translate in multi-center RCTs. Heterogeneity of baseline care has been suggested to represent a major contributor to these failures of translation from single- to multi-center trials. ${ }^{158-160}$ The classic example in this regard is the companion paper to the multi-center trial of the effect of therapeutic hypothermia in severe TBI. ${ }^{161} \mathrm{In}$ that article, it was shown that despite targeting consistent ICP and CPP thresholds across the centers, background care varied enormously in the approaches taken to achieve those goals, notably in the selection of the use of fluids or pressors to support CPP. It is exciting that important comparative effectiveness trials are underway in adults (CENTER-TBI) and children (ADAPT) with severe TBI to try to define the best elements of standard care that are supported by the guidelines. ${ }^{159,162}$ These trials allow the centers that are involved to use their usual approach and then statistically compare and analyze the findings across a thousand or more patients. The ADAPT trial recently completed follow-up on $\sim 1000$ children with severe TBI using that approach and the results are eagerly anticipated. Such an approach should aid in defining the best background care upon which future RCTs of novel therapies can be based-reducing therapeutic heterogeneity.

Adaptive trial design represents a novel approach that has great potential for TBI. Rather than simply randomizing the sample size target for a clinical trial equally to the test therapy versus placebo, a 
response-adaptive randomization can be used that allows, in a blinded fashion, a computer algorithm to start randomizing patients to the group that is showing favorable effects-for example, using one or more surrogate endpoints. ${ }^{163}$ If the therapy continues to show benefit, it can allow statistical significance to be achieved, often at much reduced sample sizes, and thus can provide a faster answer, with fewer patients exposed to the inferior therapy, and at less cost. In adaptive designs, it is also possible to compare multiple therapies simultaneously. This approach is being used clinically in cancer research, and in acute medicine for conditions such as sepsis and epilepsy. ${ }^{163-165}$

Continuous data acquisition is now replacing the traditional approach of nurse data entry of hourly physiological findings in the care of patients with severe TBI. The broad implementation of electronic medical record (EMR) systems in clinical practice has facilitated the introduction of continuous data acquisition approaches in clinical research. This allows the interrogation of thousands of data points in an unbiased manner and has recently contributed to reports on the treatment of intracranial hypertension in TBI that are changing guidelines. ${ }^{166,167}$ These data are more accurate than intermittently recorded vital signs, and lack the human "filter" that may selectively document abnormal values. Raw continuous data may be parameterized in ways that offer insight into underlying biology and physiology. Beat-to-beat heart rate variability or pulse pressure variation can reveal underlying autonomic state. Similarly, the relationship between data streams, such as responsiveness of brain oxygenation or electroencephalogram waveforms in response to physiological perturbations such as a change in blood pressure, may further elucidate TBI physiology and injury phenotypes in a manner that may be dynamically updated in near real time to facilitate precision delivery of the best therapy to the right patient at the optimal timing and for the necessary duration.

Finally, big data approaches are being used in both pre-clinical and clinical research in TBI and related acute neurological conditions. Recently, Adam Ferguson's group interrogated an archived database from the Multi-center Animal Spinal Cord Injury Study (MASCIS) from the late 1990s using a big data approach to identify a powerful association between perioperative hypertension and unfavorable outcome in the weight-drop model of spinal cord injury in rats. ${ }^{168}$ The initial finding in 72 animals was validated in a cross-validation set of 154 animals from the same 3-year trial. Similarly, with the incorporation of the EMR into routine patient care and clinical research, novel study designs are producing exciting findings in the setting of ICU medicine including TBI. Semler and colleagues ${ }^{169}$ recently compared the use of balanced crystalloids versus normal saline in critically ill adults. Intravenous crystalloid use is ubiquitous in the critically ill and normal saline is the most often used fluid. Despite this, data suggest that normal saline is associated with hyperchloremia, metabolic acidosis, acute kidney injury (AKI), and death, particularly in critically ill patients receiving enormous amounts. Crystalloids with an electrolyte composition closer to plasma-that is, "balanced crystalloids" including Plasmalyte and Lactated Ringers are available alternatives increasingly used, and trials suggest advantages on AKI and death. Investigators at Vanderbilt Medical Center tested this hypothesis using a "big data" EMR approach and carried out a pragmatic, cluster-randomized, multiple-cross-over trial. They alternated the use of either normal saline or balanced crystalloid in five ICUs on a monthly basis-without the need to randomize or obtain informed consent. In 2 years, they compared outcomes in $>15,000$ ICU patients. They reported a $1.1 \%$ difference in the pri- mary outcome in favor of balanced crystalloid versus normal saline (using a composite outcome including mortality). With that sample, the finding was statistically significant $(p<0.05)$. A total of 57 fewer deaths were reported with balanced crystalloid. This finding is potentially important given that 5 million patients are admitted to ICUs every year. Thus, a switch to balanced crystalloids could potentially save 19,000 ICU patients each year. It is noteworthy that benefit in favor of balanced versus normal saline was observed in all of the ICUs except the cardiac ICU and in patients with TBI, where the trend was actually in favor of normal saline. There is potential concern over brain edema with the use of balanced crystalloids in TBI given that they are slightly hypo-osmolar in contrast to normal saline. This big data EMR strategy has obvious potential and additional studies using this approach will likely emerge in TBI.

It is important to keep in mind the potential precarious balance between big-data- versus medicine-based strategies directing patient care. There are clear benefits to both approaches. Nevertheless, the overall approach may need to be tailored depending on the question being asked, specific factors such as the risks/benefits, and the available data. Big data may point us in the right direction (i.e., fluid management), and precision medicine may then be able to sort out the details regarding the specific patient populations that would benefit.

\section{Avoiding Misconceptions that Could Stifle or Misdirect Traumatic Brain Injury Therapy Development in the Golden Age of Traumatic Brain Injury Research}

In the face of all of this optimism and exciting new research on TBI, two issues deserve brief discussion that, in our opinion, could stifle or misdirect TBI therapy development. Recently, there has been a suggestion that research using animals with a lissencephalic brain, such as rats or mice, fails to model human TBI given the lower percentage of white matter in the rodent brain. Proponents of the idea believe that use of gyrencephalic animals, such as pigs, ferrets, or primates, is necessary for successful clinical translation. ${ }^{170,171}$ Our group has had extensive experience studying TBI and other forms of acute brain injury across all of these species and discussed this question in a review published nearly two decades ago. ${ }^{172}$ We support the use of a broad spectrum of models and species, from in vitro to large animal. Strongly supporting the fidelity between rodent models and the pathobiology of human TBI is the recent report of Jenkins and colleagues, ${ }^{173}$ which studied the dopamine system in 42 humans with TBI, using ${ }^{123}$ I-Ioflupane single-photon emission computed tomography scans to assess dopamine transporter levels coupled to advanced MRI techniques. They demonstrated that moderate-severe TBI patients had clear evidence of reduced specific binding ratios for the dopamine transporter in the striatum, despite a relative lack of evidence of macroscopic lesions in the striatum and no relationship between presence of lesions and dopamine-transporter-specific binding ratio abnormalities. The patients with low caudate dopamine transporter binding ratios also showed impaired cognitive function. These findings are consistent with another clinical positron emission tomography study by Wagner and colleagues. ${ }^{174}$ Further, the findings mirrored those reported in the CCI model in rats in a series of studies from the laboratories of Ed Dixon and Amy Wagner from our group, ${ }^{175-178}$ including studies on the impact of treatment with methylphenidate-findings that were outlined and cited by Jenkins and colleagues. ${ }^{173}$ Also, one of the only positive multi-center clinical 
trials in TBI tested the use of amantadine ${ }^{179}$ and was based importantly on that rodent work. These findings support the current pharmacological approaches taken in TBI rehabilitation and strongly support pre-clinical studies on therapy development in rodent models.

There are many other obvious examples, where important findings in pre-clinical studies in rodent models recapitulate the human condition and/or suggest vital avenues that should be pursued. For example, the recent findings of the spreading of Tau pathology observed in mice in the CCI model mirror the diffuse Tau deposition observed in patients after a single TBI as reported in mice and humans by Zanier and colleagues. ${ }^{180}$ Similarly, amyloid- $\beta$ expression after CCI in mice genetically modified to express human amyloid- $\beta$ mirror the findings observed in acute biopsy samples from patients with severe TBI as reported by Ikonomovic and colleagues. ${ }^{181,182}$ The potentially important new finding of cortical layer 5 neuronal vulnerability observed in mice after TBI by John Povlishock's group suggests an important shift in thinking about axonal injury, and this novel mechanism should be explored in the human brain. ${ }^{183}$ Finally, the series of findings from the laboratory of Robert Clark demonstrating parallel molecular neuronal death pathways between rodents, as studied in CCI, and human brain samples from patients with severe TBI, strongly support the transitional relevance of rodent models (reviewed in a previous work ${ }^{184}$ ). Countless additional examples could be cited, ${ }^{104-110}$ among others. Recent advancements in the biomechanical modeling of TBI are also closing the gap between human and rodent force loading mechanics, notably in the setting of mild TBI. New concussion models have been de- veloped in rodents to better reproduce the loading conditions associated with impact-induced rotation. ${ }^{185,186}$

Similar concerns have been raised for the use of rodents to develop therapies for inflammatory disorders where studies have suggested that the inflammatory response to endotoxin in mice fails to mimic the human response, ${ }^{187}$ although the findings were disputed in reanalysis. ${ }^{188}$ However, mouse models have been instrumental to the successful development of new therapies for human inflammatory disorders, such as rheumatoid arthritis and asthma, along with disorders involving the CNS, such as multiple sclerosis (reviewed in a previous work ${ }^{189}$ ). Therapy development in in vivo models of TBI should utilize all of the potential modeling resources that have been developed by our field. Also, the rich repository of information in the literature on the effects of various therapies on outcomes in pre-clinical rat, mouse, and pig models of TBI should be more fully and carefully evaluated (Fig. 3).

Finally, much of the recent focus of research has been on mild TBI, as a result of increased societal awareness of its prevalence and links to conditions such as chronic traumatic encephalopathy, and neurodegenerative disease, along with the occurrence of these conditions in professional athletes and military service members with high visibility in the lay press. Nevertheless, as outlined in this review, severe TBI also remains of great public health importance. Severe TBI accounts for the overwhelming portion of the observed mortality, greatly impacts the life of each individual and their family, and has a tremendous societal and economic toll. ${ }^{1}$ The economic cost of TBI in 2010, including direct and indirect medical

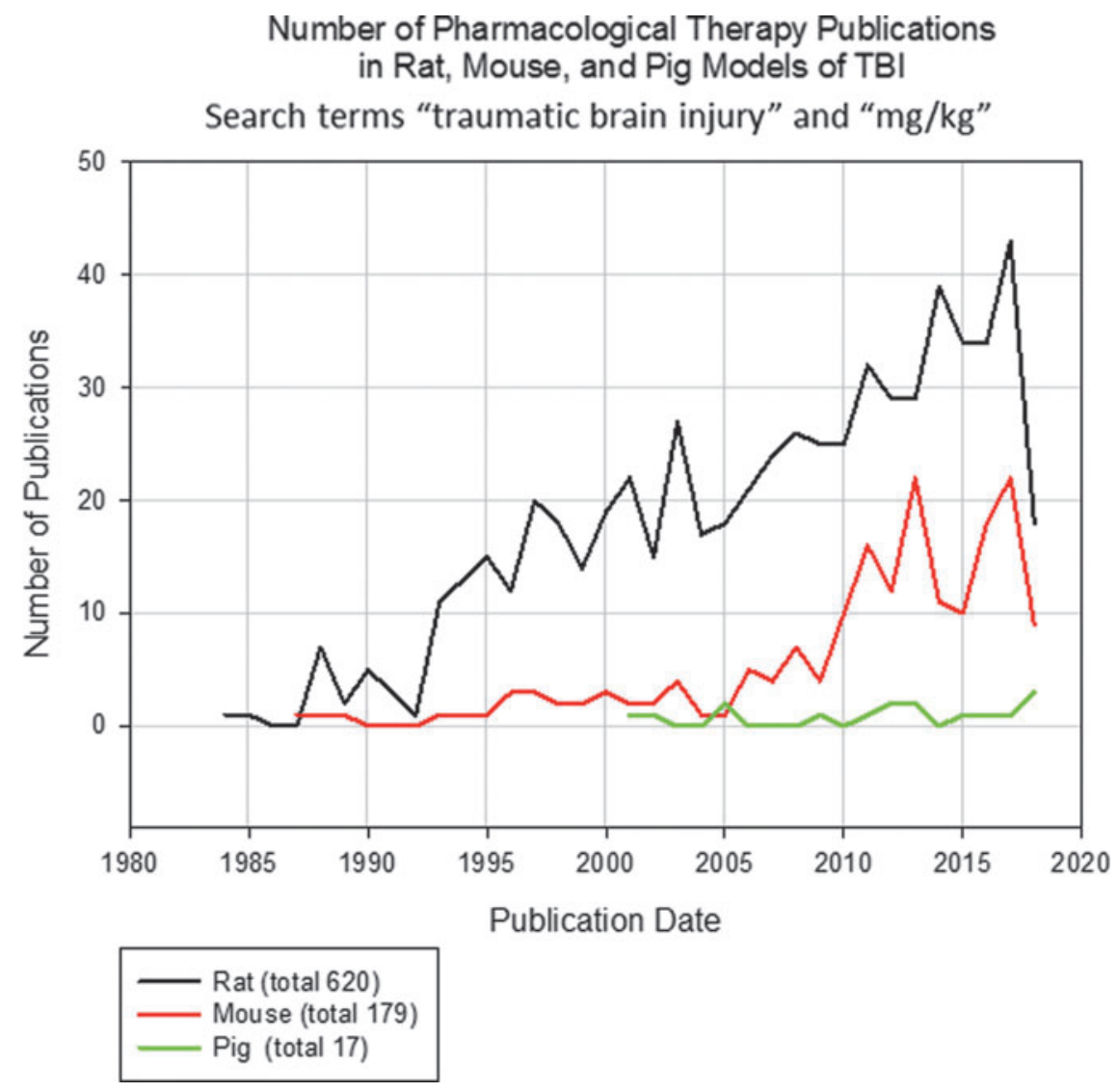

FIG. 3. Publications of studies on drug therapies in rat, mouse, and pig models of TBI since 1980 based on interrogation of PubMed. An extensive repository of information on the effects of a wide variety of therapies on outcomes in pre-clinical models of TBI, particularly in rodents, represents a resource that merits more comprehensive and systematic evaluation, particularly for future consortium-based testing of therapies across models and species. Please see text for details. TBI, traumatic brain injury. 


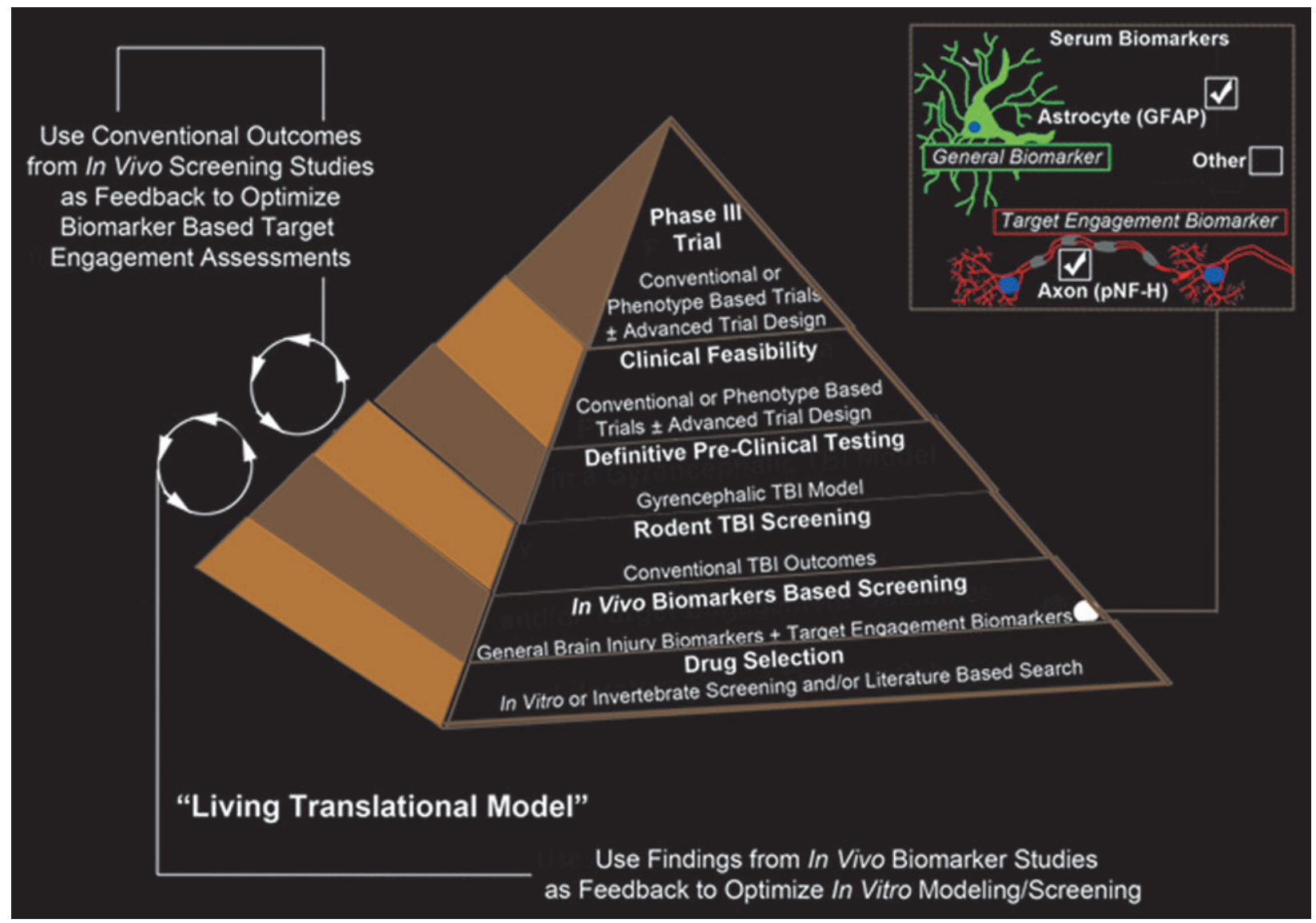

FIG. 4. Construct of a possible approach to therapy development for severe TBI from drug selection and initial screening, through to small animal testing with pharmacodynamics/response biomarkers addressing target engagement readouts, then progressing to conventional small and large animal in vivo testing, and finally on to clinical feasibility and safety trials and ultimately phase III trials. The clinical trials could represent either conventional severe TBI populations across the full spectrum or phenotype-based trials using either standard or advanced trial designs. Feedback loops to inform earlier screening approaches on their ability to predict at more advanced levels are also shown. Please see text for details. GFAP, glial fibrillary acidic protein; pNF-H, phospho-neurofilament-H; TBI, traumatic brain injury.

costs, was estimated to be $\sim \$ 76.5$ billion. And, remarkably, the cost of fatal TBIs and TBIs requiring hospitalization, most of which are severe, account for $\sim 90 \%$ of the total TBI medical costs. Thus, the focus of TBI research moving forward should address the full continuum of injury severity.

\section{Conclusions}

Spearheaded by the enhanced awareness of the importance of TBI in civilian and military health, the possible contribution of modern combat casualties with body armor, the link between TBI and chronic neurodegenerative disease, and resultant increases in funding for TBI research, a number of new approaches to both pre-clinical and clinical investigation are being utilized, supporting the notion that we have entered a golden age of TBI research and are on the cusp of therapeutic breakthroughs. The ultimate goal is to define and develop robust therapies with reproducible effects shown in a step-wise fashion in a pre-clinical consortium, define and target the optimal specific clinical TBI phenotype for the therapy, define the optimal dosing and treatment regimen, use the best background care consistently across a multicenter platform, carry out the study with state-of-the-art adaptive trial design, and monitor target engagement at the bedside. A synthesis of these new approaches that links the pre-clinical and clinical arenas is provided in Figure 4.
An optimal link between the pre-clinical and clinical investigations is also essential to the successful development and translation of new therapies and improved patient outcomes. In the spirit of bridging pre-clinical and clinical research, we also hope that the timing of this review, near the 2019 meeting of the National Neurotrauma Society's Annual Meeting in Pittsburgh, Pennsylvania (the city with the largest number of bridges in the United States, and well known for its TBI research) further facilitates success in this regard during the golden age of TBI research.

\section{Acknowledgments}

We thank the PA Cures (PA RFA67-49), the U.S. Department of Defense WH81XWH-14-2-0018, US Army grant W81XWH-17-C0064, the NIH NINDS (K23NS101036; to R.M.J.), (NS087978; to P.M.K./E.K.J.), (T32HD040686 and KL2TR00185603; to A.T.B.), and the University of Pittsburgh Deans Faculty Advancement Award (to R.M.J.) for generous support.

\section{Author Disclosure Statement}

Dr. Ruchira Jha is a Consultant for Biogen. Dr. D. Lansing Taylor is the co-founder and chairman of SpIntellx Inc., co-founder and advisor of Cernostics, Inc., and advisor of Von Baer Wolff, Inc. The remaining authors declare no competing financial interests exist. 


\section{References}

1. Centers for Disease Control and Prevention. Traumatic Brain InjuryRelated Emergency Department Visits, Hospitalizations, and Deaths-United States, 2007 and 2013. 2017. https://www.cdc.gov/ mmwr/volumes/66/ss/ss6609a1.htm. Accessed September 15, 2018.

2. http://apps.webofknowledge.com/WOS_GeneralSearch_input.do? product $=$ WOS $\&$ search_mode $=$ GeneralSearch $\&$ SID $=8$ DWJT2RZzu CuyihotpB\&preferencesSaved=. Accessed April 16, 2018.

3. Kochanek, P.M., Bramlett, H., Dietrich, W.D., Dixon, C.E., Hayes, R.L., Povlishock, J., Tortella, F.C., and Wang, K.K. (2011). A novel multicenter preclinical drug screening and biomarker consortium for experimental traumatic brain injury: Operation Brain Trauma Therapy. J. Trauma 71, 1 Suppl., S15-S24.

4. Ji, J., Kline, A.E., Amoscato, A., Arias, A.S., Sparvero, L.J., Tyurin, V.A., Tyurina, Y.Y., Fink, B., Manole, M.D., Puccio, A.M., Okonkwo, D.O., Cheng, J.P., Alexander, H., Clark, R.S., Kochanek, P.M., Wipf, P., Kagan, V.E., and Bayır, H. (2012). Lipidomics identifies cardiolipin oxidation as a mitochondrial target for redox therapy of brain injury. Nat. Neurosci. 15, 1407-1415.

5. Hagos, F.T., Empey, P.E., Wang, P., Ma, X., Poloyac, S.M., Bayır, H., Kochanek, P.M., Bell, M.J., and Clark, R.S.B. (2018). Exploratory application of Neuro-pharmacometabolomics in severe childhood traumatic brain injury. Crit. Care Med. 46, 1471-1479.

6. Miller Ferguson, N., Sarnaik, A., Miles, D., Shafi, N., Peters, M.J., Truemper, E., Vavilala, M.S., Bell, M.J., Wisniewski, S.R., Luther, J.F., Hartman, A.L., and Kochanek, P.M.; for the Investigators of the ADAPT Trial. (2017). Abusive head trauma and mortality-an analysis from an international comparative study of children with severe traumatic brain injury. Crit. Care Med. 45, 1398-1407.

7. Jha, R.M., Elmer, J., Zusman, B., Puccio, A., Okonkwo, D., Shutter, L., Wallisch, J., Conley, Y., and Kochanek, P.M. (2018). Intracranial pressure trajectories a novel tool to inform severe TBI phenotypes. Crit. Care Med. 46, 1792-1802.

8. U.S. Food and Drug Administration. About Biomarkers and Qualification. Page last updated: August 2, 2018. https://www.fda.gov/Drugs/ DevelopmentApprovalProcess/DrugDevelopmentToolsQualification Program/BiomarkerQualificationProgram/ucm535922.htm\#BEST_ Glossary. Accessed September 14, 2018.

9. Campbell, B.C., Mitchell, P.J., Kleinig, T.J., Dewey, H.M., Churilov, L., Yassi, N., Yan, B., Dowling, R.J., Parsons, M.W., Oxley, T.J., Wu, T.Y., Brooks, M., Simpson, M.A., Miteff, F., Levi, C.R., Krause, M., Harrington, T.J., Faulder, K.C., Steinfort, B.S., Priglinger, M., Ang, T., Scroop, R., Barber, P.A., McGuinness, B., Wijeratne, T., Phan, T.G., Chong, W., Chandra, R.V., Bladin, C.F., Badve, M., Rice, H., de Villiers, L., Ma, H., Desmond, P.M., Donnan, G.A., and Davis, S.M.; EXTEND-IA Investigators. (2015). Endovascular therapy for ischemic stroke with perfusion-imaging selection. $\mathrm{N}$. Engl. J. Med. 372, 1009-1018.

10. Goyal, M., Demchuk, A.M., Menon, B.K., Eesa, M., Rempel, J.L., Thornton, J., Roy, D., Jovin, T.G., Willinsky, R.A., Sapkota, B.L., Dowlatshahi, D., Frei, D.F., Kamal, N.R., Montanera, W.J., Poppe, A.Y., Ryckborst, K.J., Silver, F.L., Shuaib, A., Tampieri, D., Williams, D., Bang, O.Y., Baxter, B.W., Burns, P.A., Choe, H., Heo, J.H., Holmstedt, C.A., Jankowitz, B., Kelly, M., Linares, G., Mandzia, J.L., Shankar, J., Sohn, S.I., Swartz, R.H., Barber, P.A., Coutts, S.B., Smith, E.E., Morrish, W.F., Weill, A., Subramaniam, S., Mitha, A.P., Wong, J.H., Lowerison, M.W., Sajobi, T.T., and Hill, M.D.; ESCAPE Trial Investigators. (2015). Randomized assessment of rapid endovascular treatment of ischemic stroke. N. Engl. J. Med. 372, 1019-1030.

11. Goyal, M., Menon, B.K., van Zwam, W.H., Dippel, D.W., Mitchell, P.J., Demchuk, A.M., Dávalos, A., Majoie, C.B., van der Lugt, A., de Miquel, M.A., Donnan, G.A., Roos, Y.B., Bonafe, A., Jahan, R., Diener, H.C., van den Berg, L.A., Levy, E.I., Berkhemer, O.A., Pereira, V.M., Rempel, J., Millán, M., Davis, S.M., Roy, D., Thornton, J., Román, L.S., Ribó, M., Beumer, D., Stouch, B., Brown, S., Campbell, B.C., van Oostenbrugge, R.J., Saver, J.L., Hill, M.D., and Jovin, T.G.; HERMES collaborators. (2016). Endovascular thrombectomy after large-vessel ischaemic stroke: a meta-analysis of individual patient data from five randomised trials. Lancet 387, 1723-1731

12. Jacobs, S.E., Berg, M., Hunt, R., Tarnow-Mordi, W.O., Inder, T.E., and Davis, P.G. (2013). Cooling for newborns with hypoxic ischaemic encephalopathy. Cochrane Database Syst. Rev. (1), CD003311.
13. Wright, D.W., Yeatts, S.D., Silbergleit, R., Palesch, Y.Y., Hertzberg, V.S., Frankel, M., Goldstein, F.C., Caveney, A.F., Howlett-Smith, H., Bengelink, E.M., Manley, G.T., Merck, L.H., Janis, L.S., and Barsan, W.G.; NETT Investigators. (2014). Very early administration of progesterone for acute traumatic brain injury. N. Engl. J. Med. 371, 2457-2466.

14. Nichol, A., French, C., Little, L., Haddad, S., Presneill, J., Arabi, Y., Bailey, M., Cooper, J., Duranteau, J., Huet, O., Mark, A., McArthur, C., Pettila, V., Skrifvars, M., Vallance, S., Varma, D., Wills, J., and Bellomo, R. (2015). Erythropoietin in traumatic brain injury (EPOTBI): a double-blind randomized controlled trial. Lancet 386, 2499 2506.

15. Robertson, C.S., Hannay, H.J., Yamal, J.M., Gopinath, S., Goodman, J.C., Tilley, B.C., Epo Severe TBI Trial Investigators, Baldwin, A., Rivera Lara, L., Saucedo-Crespo, H., Ahmed, O., Sadasivan, S., Ponce, L., Cruz-Navarro, J., Shahin, H., Aisiku, I.P., Doshi, P., Valadka, A., Neipert, L., Waguspack, J.M., Rubin, M.L., Benoit, J.S., and Swank, P. (2014). Effect of erythropoietin and transfusion threshold on neurological recovery after traumatic brain injury: a randomized clinical trial. JAMA 312, 36-47.

16. Kontos, A.P., Collins, M.W., Holland, C.L., Reeves, V.L., Edelman, K., Benso, S., Schneider, W., and Okonkwo, D. (2018). Preliminary evidence for improvement in symptoms, cognitive, vestibular, and oculomotor outcomes following targeted intervention with chronic mTBI patients. Mil. Med. 183, Suppl. 1, 333-338.

17. Blennow, K., Brody, D.L., Kochanek, P.M., Levin, H., McKee, A., Ribbers, G.M., Yaffe, K., and Zetterberg, H. (2016). Traumatic brain injuries. Nat. Rev. Dis. Primers. 2, 16084.

18. Bombardier, C.H., Fann, J.R., Ludman, E.J., Vannoy, S.D., Dyer, J.R., Barber, J.K., and Temkin, N.R. (2017). The relations of cognitive, behavioral, and physical activity variables to depression severity in traumatic brain injury: reanalysis of data from a randomized controlled trial. J. Head Trauma Rehabil. 32, 343-353.

19. Carney, N., Totten, A.M., O'Reilly, C., Ullman, J.S., Hawryluk, G.W., Bell, M.J., Bratton, S.L., Chesnut, R., Harris, O.A., Kissoon, N., Rubiano, A.M., Shutter, L., Tasker, R.C., Vavilala, M.S., Wilberger, J., Wright, D.W., and Ghajar J. (2017). Guidelines for the management of severe traumatic brain injury, fourth edition. Neurosurgery $80,6-15$.

20. Kochanek, P.M., Carney, N., Adelson, P.D., Ashwal, S., Bell, M.J., Bratton, S., Carson, S., Chesnut, R.M., Ghajar, J., Goldstein, B., Grant, G.A., Kissoon, N., Peterson, K., Selden, N.R., Tasker, R.C., Tong, K.A., Vavilala, M.S., Wainwright, M.S., and Warden, C.R. (2012). Guidelines for the acute medical management of severe traumatic brain injury in infants, children, and adolescents-second edition. Pediatr. Crit. Care Med. 13, Suppl. 1, S1-S82.

21. Chesnut, R.M., Temkin, N., Carney, N., Dikmen, S., Rondina, C., Videtta, W., Petroni, G., Lujan, S., Pridgeon, J., Barber, J., Machamer, J., Chaddock, K., Celix, J.M., Cherner, M., and Hendrix, T.; Global Neurotrauma Research Group. (2012). A trial of intracranialpressure monitoring in traumatic brain injury. N. Engl. J. Med. 367, 2471-2481.

22. Kochanek, P.M., Jackson, T., Miller Ferguson, N., Carlson, S., Simon, D., Brockman, E., Bayır, H., Poloyac, S., Wagner, A.K., Kline, A.E., Empey, P., Kagan, V., Jackson, E.K., Clark, R.S.B., and Dixon, C.E. (2015). Emerging therapies in TBI. Semin. Neurol. 35, 83-100.

23. Kochanek, P.M., Bramlett, H.M., Dixon, C.E., Shear, D.A., Dietrich, W.D., Schmid, K.E., Mondello, S., Wang, K.K., Hayes, R.L., Povlishock, J.T., and Tortella, F.C. (2016). Operation Brain Trauma Therapy: approach to modeling therapy evaluation, drug selection, and biomarker assessments, for a multi-center pre-clinical drug screening consortium for acute therapies in severe traumatic brain injury. J. Neurotrauma 33, 513-522.

24. Smith, D.H., Hicks, R., and Povlishock, J.T. (2013). Therapy development for diffuse axonal injury. J. Neurotrauma 30, 307-323.

25. Shear, D.A., Dixon, C.E., Bramlett, H.M., Mondello, S., Dietrich, W.D., Deng-Bryant, Y., Schmid, K.E., Wang, K.K., Hayes, R.L., Povlishock, J.T., Kochanek, P.M., and Tortella, F.C. (2016). Operation brain trauma therapy: nicotinamide treatment in traumatic brain injury. J. Neurotrauma 33, 523-537.

26. Bramlett, H.M., Dietrich, W.D., Dixon, C.E., Shear, D.A., Schmid, K.E., Mondello, S., Wang, K.K., Hayes, R.L., Povlishock, J.T., Tortella, F.C., and Kochanek, P.M. (2016). Operation brain trauma therapy: erythropoietin treatment in traumatic brain injury. J. Neurotrauma $33,538-552$. 
27. Dixon, C.E., Bramlett, H.M., Dietrich, W.D., Shear, D.A., Yan, H.Q. Deng-Bryant, Y., Mondello, S., Wang, K.K., Hayes, R.L., Empey, P.E., Povlishock, J.T., Tortella, F.C., and Kochanek, P.M. (2016) Operation brain trauma therapy: cyclosporine treatment in traumatic brain injury. J. Neurotrauma 33, 553-666.

28. Mountney, A., Bramlett, H.M., Dixon, C.E., Mondello, S., Dietrich, W.D., Wang, K.K., Caudle, K., Empey, P.E., Poloyac, S.M., Hayes, R.L., Povlishock, J.T., Tortella, F.C., Kochanek, P.M., and Shear, D.A. (2016). Operation brain trauma therapy: simvastatin treatment in traumatic brain injury. J. Neurotrauma 33, 567-580.

29. Browning, M., Shear, D.A., Bramlett, H.M., Dixon, C.E., Mondello, S., Schmid, K.E., Poloyac, S.M., Dietrich, W.D., Hayes, R.L., Wang, K.K., Povlishock, J.T., Tortella, F.C., and Kochanek, P.M. (2016). Operation brain trauma therapy: levetiracetam treatment in traumatic brain injury. J. Neurotrauma 33, 581-594.

30. Mondello, S., Shear, D.A., Bramlett, H.M., Dixon, C.E., Schmid, K.E., Dietrich, W.D., Wang, K.K., Hayes, R.L., Glushakova, O. Catania, M., Richieri, S.P., Povlishock, J.T., Tortella, F.C., and Kochanek, P.M. (2016). Insight into preclinical models of traumatic brain injury using circulating brain damage biomarkers: operation brain trauma therapy. J. Neurotrauma 33, 595-605.

31. Kochanek, P.M., Bramlett, H.M., Shear, D.A., Dixon, C.E., Mondello, S., Dietrich, W.D., Hayes, R.L., Wang, K.K., Poloyac, S.M. Empey, P.E., Povlishock, J.T., Mountney, A., Browning, M., DengBryant, Y., Yan, H.Q., Jackson, T.C., Catania, M., Glushakova, O., Richieri, S.P., and Tortella, F.C. (2016). Operation brain trauma therapy: synthesis of findings, current investigations, and future directions. J. Neurotrauma 33, 606-614.

32. Kochanek, P.M., Bramlett, H.M., Dixon, C.E., Dietrich, W.D., Mondello, S., Wang, K.K., Hayes, R.L., Lafrenaye, A.D., Povlishock, J.T., Tortella, F.C., Poloyac, S.M., Empey, P.E., and Shear, D.A. (2018). Operation brain trauma therapy: 2016 update. Mil. Med. 183, 303-312.

33. Kochanek, P.M., Dixon, C.E., Mondello, S., Wang, K.K., Lafrenaye, A., Bramlett, H.M., Dietrich, W.D., Hayes, R.L., Shear, D.A., Gilsdorf, J.S., Catania, M., Poloyac, S.M., Empey, P.E., Jackson, T.C., and Povlishock, J.T. (2018). Multi-center pre-clinical consortia to enhance translation of therapies and biomarkers for traumatic brain injury: Operation Brain Trauma Therapy and beyond. Front. Neurol. 9, 640 .

34. Yang, Z., Zhu, T., Mondello, S., Akel, M., Wong, A.T., Kothari, I.M., Lin, F., Shear, D.A., Gilsdorf, J.S., Leung, L.Y., Bramlett, H.M., Dixon, C.E., Dietrich, W.D., Hayes, R.L., Povlishock, J.T., Tortella, F.C., Kochanek, P.M., and Wang, K.K.W. (2019). Serumbased phospho-neurofilament-heavy protein as theranostic biomarker in three models of traumatic brain injury: an Operation Brain Trauma Therapy study. J. Neurotrauma 36, 348-359.

35. Smith, D.H., Hicks, R.R., Johnson, V.E., Bergstrom, D.A., Cummings, D.M., Noble, L.J., Hovda, D., Whalen, M., Ahlers, S.T., LaPlaca, M. Tortella, F.C., Duhaime, A.C., and Dixon, C.E. (2015). Pre-clinical traumatic brain injury common data elements: toward a common language across laboratories. J. Neurotrauma 32, 1725-1735.

36. Busto, R., Dietrich, W.D., Globus, M.Y., Valdés, I., Scheinberg, P., and Ginsberg, M.D. (1987). Small differences in intra-ischemic brain temperature critically determine the extent of ischemic neuronal injury. J. Cereb. Blood Flow Metab. 7, 729-738

37. Statler, K.D., Jenkins, L.W., Dixon, C.E., Clark, R.S., Marion, D.W. and Kochanek, P.M. (2001). The simple model versus the super model: translating experimental traumatic brain injury research to the bedside. J. Neurotrauma 18, 1195-1206.

38. Lithgow, G.J., Driscoll, M., and Phillips, P. (2017). A long journey to reproducible results. Nature 548, 387-388.

39. DeRidder, M.N., Simon, M.J., Siman, R., Auberson, Y.P., Raghupathi, R., and Meaney, D.F. (2006). Traumatic mechanical injury to the hippocampus in vitro causes regional caspase- 3 and calpain activation that is influenced by NMDA receptor subunit composition. Neurobiol. Dis. 22, 165-176.

40. López-García, I., Gerő, D., Szczesny, B., Szoleczky, P., Olah, G. Módis, K., Zhang, K., Gao, J., Wu, P., Sowers, L.C., DeWitt, D. Prough, D.S., and Szabo C. (2018). Development of a stretchinduced neurotrauma model for medium-throughput screening in vitro: identification of rifampicin as a neuroprotectant. Br. J. Pharmacol. 175, 284-300.

41. Du, L., Empey, P.E., Ji, J., Chao, H., Kochanek, P.M., Bayır, H., and Clark, R.S.B. (2016). Probenecid and N-acetylcysteine prevent loss of intracellular glutathione and inhibit neuronal death after mechanical stretch injury in vitro. J. Neurotrauma 33, 1913-1917.

42. Medda, X., Mertens, L., Versweyveld, S., Diels, A., Barnham, L., Bretteville, A., Buist, A., Verheyen, A., Royaux, I., Ebneth, A., and Cabrera-Socorro, A. (2016). Development of a scalable, highthroughput-compatible assay to detect tau aggregates using iPSCderived cortical neurons maintained in a three-dimensional culture format. J. Biomol. Screen. 21, 804-815.

43. Sherman, S.A., Phillips, J.K., Costa, J.T., Cho, F.S., Oungoulian, S.R., and Finan, J.D. (2016). Stretch injury of human induced pluripotent stem cell derived neurons in a 96 well format. Sci. Rep. 6, 34097

44. Jackson, T., Kotermanski, S.E., Jackson, E.K., and Kochanek, P.M (2018). BrainPhys $\subset$ increases neurofilament levels in CNS cultures, and facilitates investigation of axonal damage after a mechanical stretch-injury in vitro. Exp. Neurol. 300, 232-246.

45. Dutta, D., Heo, I., and Clevers, H. (2017). Disease modeling in stem cell-derived 3D organoid systems. Trends Mol. Med. 23, 393-410.

46. Low, L.A., and Tagle, D.A. (2017). Tissue chips-innovative tools for drug development and disease modeling. Lab Chip. 17, 30263036 .

47. Ewart, L., Fabre, K., Chakilam, A., Dragan, Y., Duignan, D.B., Eswaraka, J., Gan, J., Guzzie-Peck, P., Otieno, M., Jeong, C.G., Keller, D.A., de Morais, S.M., Phillips, J.A., Proctor, W., Sura, R., Van Vleet, T., Watson, D., Will, Y., Tagle, D., and Berridge, B. (2017). Avigating tissue chips from development to dissemination: a pharmaceutical industry perspective. Exp. Biol. Med. 242, 1579-1585.

48. LaPlaca, M.C., Cullen, D.K., McLoughlin, J.J., and Cargill, R.S. II. (2005). High rate shear strain of three-dimensional neural cell cultures: a new in vitro traumatic brain injury model. J. Biomech. 38,1093-1105.

49. Li, X., George, S.M., Vernetti, L., Gough, A.H., and Taylor, D.L. (2018). A glass-based, continuously zonated and vascularized human liver acinus microphysiological system (vLAMPS) designed for experimental modeling of diseases and ADME/TOX. Lab. Chip. 18, 2614-2631.

50. Deveau, A.P., Bentley, V.L., and Berman, J.N. (2017). Using zebrafish models of leukemia to streamline drug screening and discovery. Exp. Hematol. 45, 1-9.

51. McCutcheon, V., Park, E., Liu, E., Sobhebidari, P., Tavakkoli, J., Wen, X.Y., Baker, A.J. (2017). A novel model of traumatic brain injury in adult zebrafish demonstrates response to injury and treatment comparable with mammalian models. J. Neurotrauma 34,13821393.

52. Katzenberger, R.J., Loewen, C.A., Wassarman, D.R., Petersen, A.J., Ganetzky, B., and Wassarman, D.A. (2013). A Drosophila model of closed head traumatic brain injury. Proc. Natl. Acad. Sci. U. S. A. 110, E4152-E4159.

53. Vaughan, L., Ranganathan, P., Kumar, R.G., Rubin, J., and Wagner, A.K. (2017). Mathematical modeling of neuroinflammation in severe clinical traumatic brain injury. J. Neurotrauma 34, A102-A103.

54. Stern, A.M., Schurdak, M.E., Bahar, I., Berg, J.M., and Taylor, D.L. (2016). A perspective on implementing a quantitative systems pharmacology platform for drug discovery and the advancement of personalized medicine. J. Biomol. Screen. 21, 521-534.

55. Sorger, P.K., Allerheiligen, S.R.B., Abernethy, D.R., Altman, R.B., Brouwer, K.L.R., Califano, A., D’Argenio, D.Z., Iyengar, R., Jusko, W.J., Lalonde, R., Lauffenburger, D.A., Shoichet, B., Stevens, J.L., Subramaniam, S., Van der Graaf, P., and Vincini, P. (2011). Quantitative and systems pharmacology in the post-genomic era: new approaches to discovering drugs and understanding therapeutic mechanisms. (NIH White Paper by the QSP Workshop Group). October 2011. https://www.nigms.nih.gov/News/reports/Documents/ SystemsPharmaWPSorger2011.pdf (last accessed January 23, 2019).

56. Pei, F., Li, H., Henderson, M.J., Titus, S.A., Jadhav, A., Simeonov, A., Cobanoglu, M.C., Mousavi, S.H., Shun, T., McDermott, L., Iyer, P., Fioravanti, M., Carlisle, D., Friedlander, R.M., Bahar, I., Taylor, D.L., Lezon, T.R., Stern, A.M., and Schurdak, M.E. (2017). Connecting neuronal cell protective pathways and drug combinations in a Huntington's Disease model through the application of quantitative systems pharmacology. Sci. Rep. 7, 17803-17819.

57. Ikonomovic, M.D., Abrahamson, E.E., Carlson, S.W., Graham, S.H., and Dixon, C.E. (2019). Novel therapies for combating chronic neuropathological sequelae of TBI. Neuropharmacology 145, Pt. B, $160-176$. 
58. Dixon, C.E., Kochanek, P.M., Yan, H.Q., Schiding, J.K., Griffith, R.G., Baum, E., Marion, D.W., and DeKosky, S.T. (1999). A oneyear study of spatial memory performance, brain morphology and cholinergic markers after moderate controlled cortical impact in rats. J. Neurotrauma 16, 109-122.

59. Bramlett, H.M., and Dietrich, W.D. (2002). Quantitative structural changes in white and gray matter 1 year following traumatic brain injury in rats. Acta Neuropathol. 103, 607-614.

60. Ferguson, S., Mouzon, B., Paris, D., Aponte, D., Abdullah, L., Stewart, W., Mullan, M., and Crawford, F. (2017). Acute or delayed treatment with Anatabine improves spatial memory and reduces pathological sequelae at late time-points after repetitive mild traumatic brain injury. J. Neurotrauma 34, 1676-1691.

61. Piao, C.S., Stoica, B.A., Wu, J., Sabirzhanov, B., Zhao, Z., Cabatbat, R., Loane, D.J., and Faden, A.I. (2013). Late exercise reduces neuroinflammation and cognitive dysfunction after traumatic brain injury. Neurobiol. Dis. 54, 252-263.

62. Bondi, C.O., Klitsch, K.C., Leary, J.B., and Kline, A.E. (2014). Environmental enrichment as a viable neurorehabilitation strategy for experimental traumatic brain injury. J. Neurotrauma 31, 873-888.

63. Brayer, S.W., Ketcham, S., Zou, H., Hurwitz, M., Henderson, C., Fuletra, J., Kumar, K., Skidmore, E., Thiels, E., and Wagner, A.K. (2015). Developing a clinically relevant model of cognitive training after experimental traumatic brain injury. Neurorehabil. Neural Repair. 29, 483-495.

64. DeWitt, D.S., Hawkins, B.E., Dixon, C.E., Kochanek, P.M., Armstead, W., Bass, C.R., Bramlett, H.M., Buki, A., Dietrich, D.W., Ferguson, A.R., Hall, E.D., Hayes, R.L., Hinds, S.R., LaPlaca, M.C., Long, J.B., Meaney, D.F., Mondello, S., Noble- Haeusslein, L.J., Poloyac, S.M., Prough, D.S., Robertson, C.S., Saatman, K.E., Shultz, S.R., Shear, D.A., Smith, D.H., Valadka, A.B., VandeVord, P. Zhang, L. (2018). Pre-clinical testing of therapies for traumatic brain injury. J. Neurotrauma 35, 2737-2754.

65. Muizelaar, J.P., Marmarou, A., Young, H.F., Choi, S.C., Wolf, A., Schneider, R.L., and Kontos, H.A. (1993). Improving the outcome of severe head injury with the oxygen radical scavenger polyethylene glycol-conjugated superoxide dismutase: a phase II trial. J. Neurosurg. 78, 375-382.

66. Narayan, R.K., Michel, M.E., Ansell, B., Baethmann, A., Biegon, A., Bracken, M.B., Bullock, M.R., Choi, S.C., Clifton, G.L., Contant, C.F., Coplin, W.M., Dietrich, W.D., Ghajar, J., Grady, S.M., Grossman, R.G., Hall, E.D., Heetderks, W., Hovda, D.A., Jallo, J., Katz, R.L., Knoller, N., Kochanek, P.M., Maas, A.I., Majde, J., Marion, D.W., Marmarou, A., Marshall, L.F., McIntosh, T.K., Miller, E., Mohberg, N., Muizelaar, J.P., Pitts, L.H., Quinn, P., Riesenfeld, G., Robertson, C.S., Strauss, K.I., Teasdale, G., Temkin, N., Tuma, R., Wade, C., Walker, M.D., Weinrich, M., Whyte, J., Wilberger, J., Young, A.B., and Yurkewicz, L. (2002). Clinical trials in head injury. J. Neurotrauma 19, 503-557.

67. Skolnick, B.E., Maas, A.I., Narayan, R.K., van der Hoop. R.G., MacAllister, T., Ward, J.D., Nelson, N.R., and Stocchetti, N.; SYNAPSE Trial Investigators. (2014). A clinical trial of progesterone for severe traumatic brain injury. N. Engl. J. Med. 371, 2467-2476.

68. Velly, L., Pellegrini, L., Guillet, B., Bruder, N., and Pisano P. (2010). Erythropoietin 2nd cerebral protection after acute injuries: a doubleedged sword? Pharmacol. Ther. 128, 445-459.

69. Sayeed, I. and Stein, D.G. (2009). Progesterone as a neuroprotective factor in traumatic and ischemic brain injury. Prog. Brain Res. 175, 219-237.

70. Rakholia, M.V., Kumar, R.G., Oh, B.M., Ranganathan, P.R., Berga, S.L., Kochanek, P.M., and Wagner, A.K. (2018). Systemic estrone production and injury-induced sex hormone steroidogenesis after severe traumatic brain injury: a prognostic indicator of traumatic brain injury-related mortality. J. Neurotrauma Aug 24. doi: 10.1089/ neu.2018.5782. [Epub ahead of print]

71. Wagner, A.K., McCullough, E.H., Niyonkuru, C., Ozawa, H., Loucks, T.L., Dobos, J.A., Brett, C.A., Santarsieri, M., Dixon, C.E., Berga, S.L., and Fabio, A. (2011). Acute serum hormone levels: characterization and prognosis after severe traumatic brain injury. J. Neurotrauma 28, 871-888.

72. Korley, F.K., Nikolian, V.C., Williams, A.M., Dennahy, I.S., Weykamp, M., and Alam, H.B. (2018). Valproic acid treatment decreases serum GFAP and UCH-L1 level in swine subjected to traumatic brain injury. J. Neurotrauma 35, 1185-1191.
73. Mokhtari, M., Nayeb-Aghaei, H., Kouchek, M., Miri, M.M., Goharani, R., Amoozandeh, A., Akhavan Salamat, S., and Sistanizad, M. (2018). Effect of memantine on serum levels of neuron-specific enolase and on the Glasgow Coma Scale in patients with moderate traumatic brain injury. J. Clin. Pharmacol. 58, 42-47.

74. Samhan-Arias, A.K., Ji, J., Demidova, O.M., Sparvero, L.J., Feng, W., Tyurin, V., Tyurina, Y.Y., Epperly, M.W., Shvedova, A.A., Greenberger, J.S., Bayır, H., Kagan, V.E., and Amoscato, A.A. (2012). Oxidized phospholipids as biomarkers of tissue and cell damage with a focus on cardiolipin. Biochim. Biophys. Acta. 1818, 2413-2423.

75. Babikian, T., Freier, M.C., Ashwal, S., Riggs, M.L., Burley, T., and Holshouser, B.A. (2006). MR spectroscopy: predicting long-term neuropsychological outcome following pediatric TBI. J. Magn. Reson. Imaging $24,801-811$.

76. Ashwal, S., Holshouser, B.A., Shu, S.K., Simmons, P.L., Perkin, R.M., Tomasi, L.G., Knierim, D.S., Sheridan, C., Craig, K., Andrews, G.H., and Hinshaw, D.B. (2000). Predictive value of proton magnetic resonance spectroscopy in pediatric closed head injury. Pediatr. Neurol. 23, 114-125.

77. Dash, R., Chung, J., Chan, T., Yamada, M., Barral, J., Nishimura, D., Yang, P.C., and Simpson, P.C. (2011). A molecular MRI probe to detect treatment of cardiac apoptosis in vivo. Magn. Reson. Med. 66, 1152-1162.

78. Foley, L.M., Hitchens, T.K., Ho, C., Janesko-Feldman, K.L., Melick, J.A., Bayir, H., and Kochanek, P.M. (2009). Magnetic resonance imaging assessment of macrophage accumulation in mouse brain after experimental traumatic brain injury. J. Neurotrauma 26, 15091519.

79. Brophy, G.M., Mazzeo, A.T., Brar, S., Alves, O.L., Bunnell, K., Gilman, C., Karnes, T., Hayes, R.L., and Bullock, R. (2013). Exposure of cyclosporin A in whole blood, cerebral spinal fluid, and brain extracellular fluid dialysate in adults with traumatic brain injury. J. Neurotrauma 30, 1484-1489.

80. Thelin, E.P., Carpenter, K.L., Hutchinson, P.J., and Helmy, A. (2017). Microdialysis monitoring in clinical traumatic brain injury and its role in neuroprotective drug development. AAPS J. 19, 367376.

81. Shannon, R.J., Timofeev, I., Nortje, J., Hutchinson, P.J., and Carpenter, K.L. (2014). Recombinant human interleukin-1 receptor antagonist in severe traumatic brain injury: a phase II randomized control trial. Br. J. Clin. Pharmacol. 78, 981-995.

82. Clark, R.S.B., Empey, P.E., Bayır, H., Rosario, B.L., Poloyac, S.M., Kochanek, P.M., Nolin, T.D., Au, A.K., Wisniewski, S.R., and Bell, M.J. (2017). Phase I randomized clinical trial of N-Acetylcysteine in combination with an adjuvant probenecid for treatment of severe traumatic brain injury in children. PLoS One 12, e0180280.

83. Hagos, F.T., Daood, M.J., Ocque, J.A., Nolin, T.D., Bayır, H., Poloyac, S.M., Kochanek, P.M., Clark, R.S.B., and Empey, P.E. (2017). Probenecid, an organic anion transporter 1 and 3 inhibitor, increases plasma and brain exposure of $\mathrm{N}$-acetylcysteine. Xenobiotica 47, 346353.

84. Jenkins, L.W., Peters, G.W., Dixon, C.E., Zhang, X., Clark, R.S., Skinner, J.C., Marion, D.W., Adelson, P.D., and Kochanek, P.M. (2002). Conventional and functional proteomics using large format two-dimensional gel electrophoresis 24 hours after controlled cortical impact in postnatal day 17 rats. J. Neurotrauma 19, 715-740.

85. Jha, R.M., Puccio, A.M., Chou, S.H., Chang, C.H., Wallisch, J.S., Molyneaux, B.J., Zusman, B.E., Shutter, L.A., Poloyac, S.M., Janesko-Feldman, K.L., Okonkwo, D.O., and Kochanek, P.M. (2017). Sulfonylurea receptor-1: a novel biomarker for cerebral edema in severe traumatic brain injury. Crit. Care Med. 45, e255e264.

86. Hoffer, M.E., Balaban, C., Slade, M.D., Tsao, J.W., Hoffer, B. (2013). Amelioration of acute sequelae of blast induced mild traumatic brain injury by $\mathrm{N}$-acetyl cysteine: a double-blind, placebo controlled study. PLoS One 8, e54163.

87. Kline, A.E., Leary, J.B., Radabaugh, H.L., Cheng, J.P., and Bondi, C.O. (2016). Combination therapies for neurobehavioral and cognitive recovery after experimental traumatic brain injury: is more better? Prog. Neurobiol. 142, 45-67.

88. Margulies, S., Anderson, G., Atif, F., Badaut, J., Clark, R., Empey, P., Guseva, M., Hoane, M., Huh, J., Pauly, J., Raghupathi, R., Scheff, S., Stein, D., Tang, H., and Hicks, M. (2016). Combination therapies 
for traumatic brain injury: retrospective considerations. J. Neurotrauma 33, 101-112.

89. Manley, G.T., MacDonald, C.L., Markowitz, A., Stephenson, D., Robbins, A., Gardner, R.C., Winkler, E.A., Bodien, Y., Taylor, S., Yue, J.K., Kannan, L., Kumar, A., McCrea, M., and Wang, K.K.W (2018). The Traumatic Brain Injury Endpoints Development (TED) initiative: progress on a public-private regulatory collaboration to accelerate diagnosis and treatment of traumatic brain injury. J. Neurotrauma. Mar 31. doi: 10.1089/neu.2016.4729. [Epub ahead of print]

90. Kochanek, P.M., and Bell, M.J. (2015). Tackling the challenges of clinical trials for severe traumatic brain injury in children: screening, phenotyping, and adapting. Crit. Care Med. 43, 1544-1546.

91. Saatman, K.E., Duhaime, A.C., Bullock, R., Maas, A.I., Valadka, A., and Manley, G.T.; Workshop Scientific Team and Advisory Panel Members. (2008). Classification of traumatic brain injury for targeted therapies. J. Neurotrauma 25, 719-738.

92. Yue, J.K., Robinson, C.K., Burke, J.F., Winkler, E.A., Deng, H., Cnossen, M.C., Lingsma, H.F., Ferguson, A.R., McAllister, T.W., Rosand, J., Burchard, E.G., Sorani, M.D., Sharma, S., Nielson, J.L., Satris, G.G., Talbott, J.F., Tarapore, P.E., Korley, F.K., Wang, K.K.W., Yuh, E.L., Mukherjee, P., Diaz-Arrastia, R., Valadka, A.B., Okonkwo, D.O., and Manley, G.T.; TRACK-TBI Investigators. (2017). Apolipoprotein E epsilon 4 (APOE-84) genotype is associated with decreased 6-month verbal memory performance after mild traumatic brain injury. Brain Behav. 7, e00791.

93. Failla, M.D., Kumar, R.G., Peitzman, A.B., Conley, Y.P., Ferrell, R.E., and Wagner, A.K. (2015). Variation in the BDNF gene interacts with age to predict mortality in a prospective, longitudinal cohort with severe TBI. Neurorehabil. Neural Repair 29, 234-246.

94. Markos, S.M., Failla, M.D., Ritter, A.C., Dixon, C.E., Conley, Y.P., Ricker, J.H., Arenth, P.M., Juengst, S.B., and Wagner. A.K. (2017) Genetic variation in the vesicular monoamine transporter: preliminary associations with cognitive outcomes after severe traumatic brain injury. J. Head Trauma Rehabil. 32, E24-E34.

95. Winkler, E.A., Yue, J.K., Ferguson, A.R., Temkin, N.R., Stein, M.B., Barber, J., Yuh, E.L., Sharma, S., Satris, G.G., McAllister, T.W., Rosand, J., Sorani, M.D., Lingsma, H.F., Tarapore, P.E., Burchard, E.G., Hu, D., Eng, C., Wang, K.K., Mukherjee, P., Okonkwo, D.O., Diaz-Arrastia, R., and Manley, G.T.; TRACK-TBI Investigators (2017). COMT Val ${ }^{158}$ Met polymorphism is associated with posttraumatic stress disorder and functional outcome following mild traumatic brain injury. J. Clin. Neurosci. 35, 109-116.

96. Adams, S.M., Conley, Y.P., Wagner, A.K., Jha, R.M., Clark, R.S., Poloyac, S.M., Kochanek, P.M., and Empey, P.E. (2017). The pharmacogenomics of severe traumatic brain injury. Pharmacogenomics $18,1413-1425$.

97. Markos, S.M., Failla, M.D., Ritter, A.C., Dixon, C.E., Conley, Y.P., Ricker, J.H., Arenth, P.M., Juengst, S.B., and Wagner, A.K. (2017). Genetic variation in the vesicular monoamine transporter: preliminary associations with cognitive outcomes after severe traumatic brain injury. J. Head Trauma Rehabil. 32, E24-E34.

98. Jha, R.M., Puccio, A.M., Okonkwo, D.O., Zusman, B.E., Park, S.Y., Wallisch, J., Empey, P.E., Shutter, L.A., Clark, R.S., Kochanek, P.M., and Conley, Y.P. (2017). ABCC8 single nucleotide polymorphisms are associated with cerebral edema in severe TBI. Neurocrit. Care 26, 213-224

99. Jha, R.M., Koleck, T.A., Puccio, A.M., Okonkwo, D.O., Park, S.Y., Zusman, B.E., Clark, R.S.B., Shutter, L.A., Wallisch, J.S., Empey, P.E., Kochanek, P.M., and Conley, Y.P. (2018). Regionally clustered $A B C C 8$ polymorphisms in a prospective cohort predict cerebral oedema and outcome in severe traumatic brain injury. J. Neurol Neurosurg. Psychiatry 89, 1152-1162.

100. Simard, J.M., Kilbourne, M., Tsymbalyuk, O., Tosun, C., Caridi, J., Ivanova, S., Keledjian, K., Bochicchio, G., and Gerzanich, V. (2009). Key role of sulfonylurea receptor 1 in progressive secondary hemorrhage after brain contusion. J. Neurotrauma 26, 2257-2267.

101. Patel, A.D., Gerzanich, V., Geng, Z., and Simard, J.M. (2010). Glibenclamide reduces hippocampal injury and preserves rapid spatial learning in a model of traumatic brain injury. J. Neuropathol. Exp. Neurol. 69, 1177-1190.

102. Zweckberger, K., Hackenberg, K., Jung, C.S., Hertle, D.N., Kiening, K.L., Unterberg, A.W., and Sakowitz, O.W. (2014). Glibenclamide reduces secondary brain damage after experimental traumatic brain injury. Neuroscience 272, 199-206.
103. Jha, R.M., Molyneaux, B.J., Jackson, T.C., Wallisch, J.S., Park, S.Y., Poloyac, S., Vagni, V.A., Janesko-Feldman, K.L., Hoshitsuki, K., Minnigh, M.B., and Kochanek, P.M. (2018). Glibenclamide produces region-dependent effects on cerebral edema in a combined injury model of traumatic brain injury and hemorrhagic shock in mice. J. Neurotrauma 35, 2125-2135.

104. Whalen, M.J., Clark, R.S., Dixon, C.E., Robichaud, P., Marion, D.W., Vagni, V., Graham, S.H., Virag, L., Hasko, G., Stachlewitz, R., Szabo, C., and Kochanek, P.M. (1999). Reduction of cognitive and motor deficits after traumatic brain injury in mice deficient in poly(ADPribose) polymerase. J. Cereb. Blood Flow Metab. 19, 835-842.

105. Sarnaik, A.A., Conley, Y.P., Okonkwo, D.O., Barr, T.L., Fink, E.L., Szabo, C., Kochanek, P.M., and Clark, R.S. (2010). Influence of PARP-1 polymorphisms in patients after traumatic brain injury. J. Neurotrauma 27, 465-471.

106. Wagner, A.K., Miller, M.A., Scanlon, J., Ren, D., Kochanek, P.M., and Conley, Y.P. (2010). Adenosine A1 receptor gene variants associated with post-traumatic seizures after severe TBI. Epilepsy Res. 90, 259-272.

107. Diamond, M.L., Ritter, A.C., Failla, M.D., Boles, J.A., Conley, Y.P. Kochanek, P.M., and Wagner, A.K. (2015). IL-1 $\beta$ associations with posttraumatic epilepsy development: a genetics and biomarker cohort study. Epilepsia 56, 991-1001.

108. Ritter, A.C., Kammerer, C.M., Brooks, M.M., Conley, Y.P., and Wagner, A.K. (2016). Genetic variation in neuronal glutamate transport genes and associations with posttraumatic seizure. Epilepsia 57, 984-993.

109. Kochanek, P.M., Vagni, V.A., Janesko, K.L., Washington, C.B., Crumrine, P.K., Garman, R.H., Jenkins, L.W., Clark, R.S., Homanics, G.E., Dixon, C.E., Schnermann, J., and Jackson, E.K. (2006). Adenosine A1 receptor knockout mice develop lethal status epilepticus after experimental traumatic brain injury. J. Cereb. Blood Flow Metab. 26, 565-575.

110. Zou, H., Brayer, S.W., Hurwitz, M., Niyonkuru, C., Fowler, L.E., and Wagner, A.K. (2013). Neuroprotective, neuroplastic, and neurobehavioral effects of daily treatment with levetiracetamin experimental traumatic brain injury. Neurorehabil. Neural Repair. 27 , 878-888.

111. Wagner, A.K., and Zitelli, K.T. (2013). A rehabilomics focused perspective on molecular mechanisms underlying neurological injury, complications, and recovery after severe TBI. Pathophysiology 20, 39-48.

112. Wagner, A.K. (2017). TBI rehabilomics research: an exemplar of a biomarker-based approach to precision care for populations with disability. Curr. Neurol. Neurosci. Rep. 17, 84.

113. Chesnut, R.M., Temkin, N., Carney, N., Dikmen, S., Rondina, C., Videtta, W., Petroni, G., Lujan, S., Pridgeon, J., Barber, J., Machamer, J., Chaddock, K., Celix, J.M., Cherner, M., and Hendrix, T.; Global Neurotrauma Research Group. (2012). A trial of intracranial-pressure monitoring in traumatic brain injury. N. Engl. J. Med. 367, 2471-2481.

114. Bennett, T.D., DeWitt, P.E., Greene, T.H., Srivastava, R., RivaCambrin, J., Nance, M.L., Bratton, S.L., Runyan, D.K., Dean, J.M., and Keenan, H.T. (2017). Functional outcome after intracranial pressure monitoring for children with severe traumatic brain injury. JAMA Pediatr. 171, 965-971.

115. Chesnut, R.M., Bleck, T.P., Citerio, G., Classen, J., Cooper, D.J., Coplin, W.M., Diringer, M.N., Grände, P.O., Hemphill, J.C. III, Hutchinson, P.J., Le Roux, P., Mayer, S.A., Menon, D.K., Myburgh, J.A., Okonkwo, D.O., Robertson, C.S., Sahuquillo, J., Stocchetti, N., Sung, G., Temkin, N., Vespa, P.M., Videtta, W., and Yonas, H. (2015). A consensus-based interpretation of the benchmark evidence from South American trials: treatment of intracranial pressure trial. J. Neurotrauma 32, 1722-1724.

116. Horvat, C.M., and Kochanek, P.M. (2017). Big data is not yet big enough to determine the influence of intracranial pressure monitoring on outcome in children with severe traumatic brain injury. JAMA Pediatr. 171, 942-943.

117. Steiner, L.A., Czosnyka, M., Piechnik, S.K., Smielewski, P., Chatfield, D., Menon, D.K., and Pickard, J.D. (2002). Continuous monitoring of cerebrovascular pressure reactivity allows determination of optimal cerebral perfusion pressure in patients with traumatic brain injury. Crit. Care Med. 30, 733-738.

118. Sorrentino, E., Diedler, J., Kasprowicz, M., Budohoski, K.P., Haubrich, C., Smielewski, P., Outtrim, J.G., Manktelow, A., Hutchinson, P.J., Pickard, J.D., Menon, D.K., and Czosnyka, M. (2012). Critical 
thresholds for cerebrovascular reactivity after traumatic brain injury. Neurocrit. Care 16, 258-266.

119. Dias, C., Silva, M.J., Pereira, E., Silva, S., Cerejo, A., Smielewski, P., Rocha, A.P., Gaio, A.R., Paiva, J.A., and Czosnyka, M. (2014). Post-traumatic multimodal brain monitoring: response to hypertonic saline. J. Neurotrauma 31, 1872-1880.

120. Howells, T., Smielewski, P., Donnelly, J., Czosnyka, M., Hutchinson, P.J.A., Menon, D.K., Enblad, P., and Aries, M.J.H. (2018). Optimal cerebral perfusion pressure in centers with different treatment protocols. Crit. Care Med. 46, e235-e241.

121. Zeiler, F.A., Donnelly, J., Menon, D.K., Smielewski, P., Hutchinson, P.J.A., and Czosnyka, M. (2018). A description of a new continuous physiological index in traumatic brain injury using the correlation between pulse amplitude of intracranial pressure and cerebral perfusion pressure. J. Neurotrauma 35, 963-974.

122. Zeiler, F.A., Donnelly, J., Smielewski, P., Menon, D.K., Hutchinson, P.J., and Czosnyka, M. (2018). Critical thresholds of intracranial pressure-derived continuous cerebrovascular reactivity indices for outcome prediction in noncraniectomized patients with traumatic brain injury. J. Neurotrauma 35, 1107-1115.

123. Okonkwo, D.O., Shutter, L.A., Moore, C., Temkin, N.R., Puccio, A.M., Madden, C.J., Andaluz, N., Chesnut, R.M., Bullock, M.R., Grant, G.A., McGregor, J., Weaver, M., Jallo, J., LeRoux, P.D., Moberg, D., Barber, J., Lazaridis, C., and Diaz-Arrastia, R.R. (2017). Brain oxygen optimization in severe traumatic brain injury phase-II: a phase II randomized trial. Crit. Care Med. 45, 1907-1914.

124. Brockman, E.C., Bayır, H., Blasiole, B., Shein, S.L., Fink, E.L., Dixon, C.E., Clark, R.S.B., Vagni, V., Ma, L., Hsia, C.J.C., Tisherman, S.A., and Kochanek, P.M. (2013). Polynitroxylated pegylated hemoglobin attenuates fluid requirements and brain edema in combined traumatic brain injury plus hemorrhagic shock in mice. J. Cereb. Blood Flow Metab. 33, 1457-1464.

125. An, N., Xu, H., Gao, W.Q., and Yang, H. (2018). Direct conversion of somatic cells into induced neurons. Mol. Neurobiol. 55, 642-651.

126. Tso, D., and McKinnon, R.D. (2015). Cell replacement therapy for central nervous system diseases. Neural Regen. Res. 10, 1356-1358.

127. Anderson, K.D., Guest, J.D., Dietrich, W.D., Bartlett Bunge, M., Curiel, R., Dididze, M., Green, B.A., Khan, A., Pearse, D.D., SarafLavi, E., Widerström-Noga, E., Wood, P., and Levi, A.D. (2017). Safety of autologous human schwann cell transplantation in subacute thoracic spinal cord injury. J. Neurotrauma 34, 2950-2963.

128. Liao, G.P., Harting, M.T., Hetz, R.A., Walker, P.A., Shah, S.K., Corkins, C.J., Hughes, T.G., Jimenez, F., Kosmach, S.C., Day, M.C., Tsao, K., Lee, D.A., Worth, L.L., Baumgartner, J.E., and Cox, C.S. Jr. (2015). Autologous bone marrow mononuclear cells reduce therapeutic intensity for severe traumatic brain injury in children. Pediatr. Crit. Care Med. 16, 245-255.

129. Wipf, P., Xiao, J., Jiang, J., Belikova, N.A., Tyurin, V.A., Fink, M.P., and Kagan, V.E. (2005). Mitochondrial targeting of selective electron scavengers: synthesis and biological analysis of hemigramicidinTEMPO conjugates. J. Am. Chem. Soc. 127, 12460-12461.

130. Lamade, A.M., Kenny, E.M., Anthonymuthu, T.S., Soysal, E., Clark, R.S.B., Kagan, V.E., and Bayır, H. (2019). Aiming for the target: mitochondrial drug delivery in traumatic brain injury. Neuropharmacology 145, Pt. B, 209-219.

131. Springer, J.E., Visavadiya, N.P., Sullivan, P.G., and Hall, E.D. (2018). Post-injury treatment with NIM811 promotes recovery of function in adult female rats after spinal cord contusion: a doseresponse study. J. Neurotrauma 35, 492-499.

132. Kannan, S., Dai, H., Navath, R.S., Balakrishnan, B., Jyoti, A., Janisse, J., Romero, R., and Kannan, RM. (2012). Dendrimer-based postnatal therapy for neuroinflammation and cerebral palsy in a rabbit model. Sci. Transl. Med. 4, 130ra46.

133. Sun, P., Liu, D.Z., Jickling, G.C., Sharp, F.R., and Yin, K.J. (2018). MicroRNA-based therapeutics in central nervous system injuries. J. Cereb. Blood Flow Metab. 38, 1125-1124.

134. Pischiutta, F., Brunelli, L., Romele, P., Silini, A., Sammali, E., Paracchini, L., Marchini, S., Talamini, L., Bigini, P., Boncoraglio, G.B., Pastorelli, R., De Simoni, M.G., Parolini, O., and Zanier, E.R. (2016). Protection of brain injury by amniotic mesenchymal stromal cell-secreted metabolites. Crit. Care Med. 44, e1118-e1131.

135. von Holstein-Rathlou, S., Petersen, N.C., and Nedergaard, M. (2018). Voluntary running enhances glymphatic influx in awake behaving, young mice. Neurosci. Lett. 662, 253-258.
136. Esenaliev, R.O., Petrov, I.Y., Petrov, Y., Guptarak, J., Boone, D.R., Mocciaro, E., Weisz, H., Parsley, M.A., Sell, S.L., Hellmich, H., Ford, J.M., Pogue, C., DeWitt, D., Prough, D.S., and Micci, M.A. (2018). Nano-pulsed laser therapy is neuroprotective in a rat model of blast-induced neurotrauma. J. Neurotrauma 35, 1510-1520.

137. Matei, N., Camara, J., McBride, D., Camara, R., Xu, N., Tang, J., and Zhang, J.H. (2018). Intranasal wnt3a attenuates neuronal apoptosis through Frz1/PIWIL1a/FOXM1 pathway in MCAO rats. J. Neurosci. $38,6787-6801$.

138. Jackson, E.K., Boison, D., Schwarzschild, M.A., and Kochanek, P.M. (2016). Purines: forgotten mediators in traumatic brain injury. J. Neurochem. 137, 142-153.

139. Hossain, I., Tan, C., Doughty, P.T., Dutta, G., Murray, T.A., Siddiqui, S., Lasemidis, L., and Arumugam, P.U. (2018). A novel microbiosensor microarray for continuous ex vivo monitoring of Gamma-Aminobutyric Acid in real-time. Front. Neurosci. 12, 500.

140. Chesnut, R.M., Marshall, L.F., Klauber, M.R., Blunt, B.A., Baldwin, N., Eisenberg, H.M., Jane, J.A., Marmarou, A., and Foulkes, M.A. (1993). The role of secondary brain injury in determining outcome from severe head injury. J. Trauma 34, 216-222.

141. Pigula, F.A., Wald, S.L., Shackford, S.R., and Vane, D.W. (1993). The effect of hypotension and hypoxia on children with severe head injuries. J. Pediatr. Surg. 28, 310-314.

142. Simon, D.W., Vagni, V.M., Kochanek, P.M., and Clark, R.S. (2016). Combined neurotrauma models: experimental models combining traumatic brain injury and secondary insults. Methods Mol. Biol. 1462, 393-411.

143. Zivi, I., Valsecchi, R., Maestri, R., Maffia, S., Zarucchi, A., Molatore, K., Vellati, E., Saltuari, L., and Frazzitta, G. (2018). Early rehabilitation reduces time to decannulation in patients with severe acquired brain injury: a retrospective study. Front. Neurol. 9, 559.

144. Wieczorek, B., Ascenzi, J., Kim, Y., Lenker, H., Potter, C., Shata, N.J., Mitchell, L., Haut, C., Berkowitz, I., Pidcock, F., Hoch, J., Malamed, C., Kravitz, T., and Kudchadkar, S.R. (2016). PICU Up!: impact of a quality improvement intervention to promote early mobilization in critically ill children. Pediatr. Crit. Care Med. 17, e559e566.

145. Choong, K., Awladthani, S., Khawaji, A., Clark, H., Borhan, A., Cheng, J., Laskey, S., Neu, C., Sarti, A., Thabane, L., Timmons, B.W., Zheng, K., and Al-Harbi, S.; Canadian Critical Care Trials Group. (2017). Early exercise in critically ill youth and children, a preliminary evaluation: the wEECYCLE Pilot Trial. Pediatr. Crit. Care Med. 18, e546-e554.

146. Houtrow, A. (2017). Early rehabilitation: a path toward optimizing function while treating critical illness in children. Pediatr. Crit. Care Med. 18, 1080-1081.

147. Kigerl, K.A., Hall, J.C., Wang, L., Mo, X., Yu, Z., and Popovich, P.G. (2016). Gut dysbiosis impairs recovery after spinal cord injury. J. Exp. Med. 213, 2603-2620.

148. Sundman, M.H., Chen, N.K., Subbian, V., and Chou, Y.H. (2017). The bidirectional gut-brain-microbiota axis as a potential nexus between traumatic brain injury, inflammation, and disease. Brain Behav. Immun. 66, 31-44.

149. Whyte, J., and Hart, T. (2003). It's more than a black box; it's a Russian doll: defining rehabilitation treatments. Am. J. Phys. Med. Rehabil. 82, 639-652.

150. Wagner, A.K., Drewencki, L.L., Chen, X., Santos, F.R., Khan, A.S., Harun, R., Torres, G.E., Michael, A.C., and Dixon, C.E. (2009). Chronic methylphenidate treatment enhances striatal dopamine neurotransmission after experimental traumatic brain injury. $\mathrm{J}$. Neurochem. 108, 986-997.

151. Phelps, T.I., Bondi, C.O., Mattiola, V.V., and Kline, A.E. (2017) Relative to typical antipsychotic drugs, aripiprazole is a safer alternative for alleviating behavioral disturbances after experimental brain trauma. Neurorehabil. Neural Repair 31, 25-33.

152. Kline, A.E., Wagner, A.K., Westergom, B.P., Malena, R.R., Zafonte, R.D., Olsen, A.S., Sozda, C.N., Luthra, P., Panda, M., Cheng, J.P., and Aslam, H.A. (2007). Acute treatment with the 5-HT(1A) receptor agonist 8-OH-DPAT and chronic environmental enrichment confer neurobehavioral benefit after experimental brain trauma. Behav. Brain Res. 177, 186-194.

153. Sta Maria, N.S., Reger, M.L., Cai, Y., Baquing, M.A.T., Buen, F., Ponnaluri, A., Hovda, D.A., Harris, N.G., and Giza, C.C. (2017). DCycloserine restores experience-dependent neuroplasticity after 
traumatic brain injury in the developing rat brain. J. Neurotrauma 34, 1692-1702.

154. Nudi, E.T., Jacqmain, J., Dubbs, K., Geeck, K., Salois, G., Searles, M.A., and Smith, J.S. (2015). Combining enriched environment, progesterone, and embryonic neural stem cell therapy improves recovery after brain injury. J. Neurotrauma 32, 1117-1129.

155. de la Tremblaye, P.B., Cheng, J.P., Bondi, C.O., and Kline, A.E. (2019). Environmental enrichment, alone or in combination with various pharmacotherapies, confers marked benefits after traumatic brain injury. Neuropharmacology 145, (Pt. A), 13-24.

156. Wright, D.W., Kellermann, A.L., Hertzberg, V.S., Clark, P.L., Frankel, M., Goldstein, F.C., Salomone, J.P., Dent, L.L., Harris, O.A., Ander, D.S., Lowery, D.W., Patel, M.M., Denson, D.D., Gordon, A.B., Wald, M.M., Gupta, S., Hoffman, S.W., and Stein, D.G. (2007). ProTECT: a randomized clinical trial of progesterone for acute traumatic brain injury. Ann. Emerg. Med. 49, 391-402, 402.e1-2.

157. Marion, D.W., Penrod, L.E., Kelsey, S.F., Obrist, W.D., Kochanek, P.M., Palmer, A.M., Wisniewski, S.R., and DeKosky, S.T. (1997). Treatment of traumatic brain injury with moderate hypothermia. $\mathrm{N}$. Engl. J. Med. 336, 540-546.

158. Bell, M.J., Adelson, P.D., Hutchison, J.S., Kochanek, P.M., Tasker, R.C., Vavilala, M.S., Beers, S.R., Fabio, A., Kelsey, S.F., and Wisniewski, S.R.; Multiple Medical Therapies for Pediatric Traumatic Brain Injury Workgroup. (2013). Differences in medical therapy goals for children with severe traumatic brain injury-an international study. Pediatr. Crit. Care Med. 14, 811-818.

159. Huijben, J.A., Volovici, V., Cnossen, M.C., Haitsma, I.K., Stocchetti, N., Maas, A.I.R., Menon, D.K., Ercole, A., Citerio, G., Nelson, D., Polinder, S., Steyerberg, E.W., Lingsma, H.F., and van der Jagt, M.; CENTER-TBI investigators and participants. (2018). Variation in general supportive and preventive intensive care management of traumatic brain injury: a survey in 66 neurotrauma centers participating in the Collaborative European NeuroTrauma Effectiveness Research in Traumatic Brain Injury (CENTER-TBI) study. Crit. Care 22, 90.

160. Meinert, E., Bell, M.J., Buttram, S., Kochanek, P.M., Balasubramani, G.K., Wisniewski, S.R., and Adelson, P.D.; Pediatric Traumatic Brain Injury Consortium: Hypothermia Investigators. (2018). Initiating nutritional support before 72 hours is associated with favorable outcome after severe traumatic brain injury in children: a secondary analysis of a randomized, controlled trial of therapeutic hypothermia. Pediatr. Crit. Care Med. 19, 345-352.

161. Clifton, G.L., Miller, E.R., Choi, S.C., and Levin, H.S. (2002). Fluid thresholds and outcome from severe brain injury. Crit. Care Med. 30, 739-745.

162. Kurz, J.E., Poloyac, S.M., Abend, N.S., Fabio, A., Bell, M.J., and Wainwright, M.S.; Investigators for the Approaches and Decisions in Acute Pediatric TBI Trial. (2016). Variation in anticonvulsant selection and electroencephalographic monitoring following severe traumatic brain injury in children-understanding resource availability in sites participating in a comparative effectiveness study. Pediatr. Crit. Care Med. 17, 649-657.

163. Talisa, V.B., Yende, S., Seymour, C.W., and Angus, D.C. (2018). Arguing for adaptive clinical trials in sepsis. Front. Immunol. 9, 1502

164. Park, J.W., Liu, M.C., Yee, D., Yau, C., van 't Veer, L.J., Symmans, W.F., Paoloni, M., Perlmutter, J., Hylton, N.M., Hogarth, M., DeMichele, A., Buxton, M.B., Chien, A.J., Wallace, A.M., Boughey, J.C., Haddad, T.C., Chui, S.Y., Kemmer, K.A., Kaplan, H.G., Isaacs C., Nanda, R., Tripathy, D., Albain, K.S., Edmiston, K.K., Elias, A.D., Northfelt, D.W., Pusztai, L., Moulder, S.L., Lang, J.E., Viscusi R.K., Euhus, D.M., Haley, B.B., Khan, Q.J., Wood, W.C., Melisko, M., Schwab, R., Helsten, T., Lyandres, J., Davis, S.E., Hirst, G.L. Sanil, A., Esserman, L.J., and Berry, D.A.; I-SPY 2 Investigators (2016). Adaptive randomization of neratinib in early breast cancer. N. Engl. J. Med. 375, 11-22.

165. Falco-Walter, J.J., and Bleck, T. (2016). Treatment of established status epilepticus. J. Clin. Med. 5, E49.

166. Shein, S.L., Ferguson, N.M., Kochanek, P.M., Bayir, H., Clark, R.S., Fink, E.L., Tyler-Kabara, E.C., Wisniewski, S.R., Tian, Y., Balasubramani, G.K., and Bell, M.J. (2016). Effectiveness of pharmacological therapies for intracranial hypertension in children with severe traumatic brain injury-results from an automated data collection system time-synched to drug administration. Pediatr. Crit. Care Med. $17,236-245$.
167. Young, A.M., Donnelly, J., Czosnyka, M., Jalloh, I., Liu, X., Aries, M.J., Fernandes, H.M., Garnett, M.R., Smielewski, P., Hutchinson, P.J., and Agrawal, S. (2016). Continuous multimodality monitoring in children after traumatic brain injury-preliminary experience. PLoS One 11, e0148817

168. Nielson, J.L., Paquette, J., Liu, A.W., Guandique, C.F., Tovar, C.A., Inoue, T., Irvine, K.A., Gensel, J.C., Kloke, J., Petrossian, T.C., Lum, P.Y., Carlsson, G.E., Manley, G.T., Young, W., Beattie, M.S., Bresnahan, J.C., and Ferguson, A.R. (2015). Topological data analysis for discovery in preclinical spinal cord injury and traumatic brain injury. Nat. Commun. 6, 8581 .

169. Semler, M.W., Self, W.H., Wanderer, J.P., Ehrenfeld, J.M., Wang, L., Byrne, D.W., Stollings, J.L., Kumar, A.B., Hughes, C.G., Hernandez, A., Guillamondegui, O.D., May, A.K., Weavind, L., Casey, J.D., Siew, E.D., Shaw, A.D., Bernard, G.R., and Rice, T.W.; SMART Investigators and the Pragmatic Critical Care Research Group. (2018). Balanced crystalloids versus saline in critically ill adults. N. Engl. J. Med. 378, 829-839.

170. Sorby-Adams, A.J., Vink, R., and Turner, R.J. (2018). Large animal models of stroke and traumatic brain injury as translational tools. Am. J. Physiol. Regul. Integr. Comp. Physiol. 315, R165-R190.

171. Schwerin, S.C., Hutchinson, E.B., Radomski, K.L., Ngalula, K.P., Pierpaoli, C.M., and Juliano, S.L. (2017). Establishing the ferret as a gyrencephalic animal model of traumatic brain injury: optimization of controlled cortical impact procedures. J. Neurosci. Methods 285, 82-96

172. Statler, K.D., Jenkins, L.W., Dixon, C.E., Clark, R.S., Marion, D.W., and Kochanek, P.M. (2001). The simple model versus the super model: translating experimental traumatic brain injury research to the bedside. J. Neurotrauma 18, 1195-1206.

173. Jenkins, P.O., De Simoni, S., Bourke, N.J., Fleminger, J., Scott, G., Towey, D.J., Svensson, W., Khan, S., Patel, M., Greenwood, R., Cole, J.H., and Sharp, D.J. (2018). Dopaminergic abnormalities following traumatic brain injury. Brain Jan 17. doi: 10.1093/brain/awx357. [Epub ahead of print]

174. Wagner, A.K., Scanlon, J.M., Becker, C.R., Ritter, A.C., Niyonkuru, C., Dixon, C.E., Conley, Y.P., and Price, J.C. (2014). The influence of genetic variants on striatal dopamine transporter and D2 receptor binding after TBI. J. Cereb. Blood Flow Metab. 34, 1328-1339.

175. Yan, H.Q., Kline, A.E., Ma, X., Li, Y., and Dixon, C.E. (2002). Traumatic brain injury reduces dopamine transporter protein expression in the rat frontal cortex. Neuroreport 13, 1899-1901.

176. Wilson, M.S., Chen, X., Ma, X., Ren, D., Wagner, A.K., Reynolds, I.J., and Dixon, C.E. (2005). Synaptosomal dopamine uptake in rat striatum following controlled cortical impact. J. Neurosci. Res. 80, 85-91.

177. Wagner, A.K., Sokoloski, J.E., Ren, D., Chen, X., Khan, A.S., Zafonte, R.D., Michael, A.C., and Dixon, C.E. (2005). Controlled cortical impact injury affects dopaminergic transmission in the rat striatum. J. Neurochem. 95, 457-465.

178. Wagner, A.K., Drewencki, L.L., Chen, X., Santos, F.R., Khan, A.S., Harun, R., Torres, G.E., Michael, A.C., and Dixon, C.E. (2009). Chronic methylphenidate treatment enhances striatal dopamine neurotransmission after experimental traumatic brain injury. J. Neurochem. 108, 986-997.

179. Giacino, J.T., Whyte, J., Bagiella, E., Kalmar, K., Childs, N., Khademi, A., Eifert, B., Long, D., Katz, D.I., Cho, S., Yablon, S.A., Luther, M., Hammond, F.M., Nordenbo, A., Novak, P., Mercer, W., Maurer-Karattup, P., and Sherer, M. (2012). Placebo-controlled trial of amantadine for severe traumatic brain injury. N. Engl. J. Med. 366, 819-826.

180. Zanier, E.R., Bertani, I., Sammali, E., Pischiutta, F., Chiaravalloti, M.A., Vegliante, G., Masone, A., Corbelli, A., Smith, D.H., Menon, D.K., Stocchetti, N., Fiordaliso, F., De Simoni, M.G., Stewart, W., and Chiesa, R. (2018). Induction of a transmissible tau pathology by traumatic brain injury. Brain 141, 2685-2699.

181. Abrahamson, E.E., Ikonomovic, M.D., Dixon, C.E., and DeKosky, S.T. (2009). Simvastatin therapy prevents brain trauma-induced increases in beta-amyloid peptide levels. Ann. Neurol. 66, 407-414.

182. Ikonomovic, M.D., Uryu, K., Abrahamson, E.E., Ciallella, J.R., Trojanowski, J.Q., Lee, V.M., Clark, R.S., Marion, D.W., Wisniewski, S.R., and DeKosky, S.T. (2004). Alzheimer's pathology in human temporal cortex surgically excised after severe brain injury. Exp. Neurol. 190, 192-203. 
183. Greer, J.E., Povlishock, J.T., and Jacobs, K.M. (2012). Electrophysiological abnormalities in both axotomized and nonaxotomized pyramidal neurons following mild traumatic brain injury. J. Neurosci. 32, 6682-6687.

184. Zhang, X., Chen, Y., Jenkins, L.W., Kochanek, P.M., and Clark, R.S. (2005). Bench-to-bedside review: apoptosis/programmed cell death triggered by traumatic brain injury. Crit. Care 9, 66-75.

185. Stemper, B.D., Shah, A.S., Pintar, F.A., McCrea, M., Kurpad, S.N., Glavaski-Joksimovic, A., Olsen, C., and Budde, M.D. (2015). Head rotational acceleration characteristics influence behavioral and diffusion tensor imaging outcomes following concussion. Ann. Biomed. Eng. 43, 1071-1088.

186. Tagge, C.A., Fisher, A.M., Minaeva, O.V., Gaudreau-Balderrama, A., Moncaster, J.A., Zhang, X.L., Wojnarowicz, M.W., Casey, N., Lu, H., Kokiko-Cochran, O.N., Saman, S., Ericsson, M., Onos, K.D., Veksler, R., Senatorov, V.V. Jr., Kondo, A., Zhou, X.Z., Miry, O., Vose, L.R., Gopaul, K.R., Upreti, C., Nowinski, C.J., Cantu, R.C., Alvarez, V.E., Hildebrandt, A.M., Franz, E.S., Konrad, J., Hamilton, J.A., Hua, N., Tripodis, Y., Anderson, A.T., Howell, G.R., Kaufer, D., Hall, G.F., Lu, K.P., Ransohoff, R.M., Cleveland, R.O., Kowall, N.W., Stein, T.D., Lamb, B.T., Huber, B.R., Moss, W.C., Friedman, A., Stanton, P.K., McKee, A.C., and Goldstein, L.E. (2018). Concussion, microvascular injury, and early tauopathy in young athletes after impact head injury and an impact concussion mouse model. Brain 141, 422-458.

187. Seok, J., Warren, H.S., Cuenca, A.G., Mindrinos, M.N., Baker, H.V., Xu, W., Richards, D.R., McDonald-Smith, G.P., Gao, H., Hennessy, L., Finnerty, C.C., López, C.M., Honari, S., Moore, E.E., Minei, J.P., Cuschieri, J., Bankey, P.E., Johnson, J.L., Sperry, J., Nathens, A.B., Billiar, T.R., West, M.A., Jeschke, M.G., Klein, M.B., Gamelli, R.L.,
Gibran, N.S., Brownstein, B.H., Miller-Graziano, C., Calvano, S.E., Mason, P.H., Cobb, J.P., Rahme, L.G., Lowry, S.F., Maier, R.V., Moldawer, L.L., Herndon, D.N., Davis, R.W., Xiao, W., and Tompkins, R.G. (2013). Inflammation and Host Response to Injury, Large Scale Collaborative Research Program. Genomic responses in mouse models poorly mimic human inflammatory diseases. Proc. Natl. Acad. Sci. U. S. A. 110, 3507-3512.

188. Takao, K., and Miyakawa, T. (2015). Genomic responses in mouse models greatly mimic human inflammatory diseases. Proc. Natl. Acad. Sci. U. S. A. 112, 1167-1172.

189. Arnett, H.A., and Viney, J.L. (2007). Considerations for the sensible use of rodent models of inflammatory disease in predicting efficacy of new biological therapeutics in the clinic. Adv. Drug Deliv. Rev. 59, 1084-1092.

Address correspondence to:

Patrick M. Kochanek, MD, MCCM Safar Center for Resuscitation Research UPMC Children's Hospital of Pittsburgh University of Pittsburgh School of Medicine John G. Rangos Research Center, 6th Floor

4401 Penn Avenue Pittsburgh, PA 15224

USA

E-mail: kochanekpm@ccm.upmc.edu 